\title{
Incorporating channel network information in hydrologic response modeling: development of a model and inter-model comparison
}

\author{
Basudev Biswal and Riddhi Singh \\ Department of Civil Engineering, Indian Institute of Technology Hyderabad, \\ Kandi, Hyderabad, 502085, India. Emails: basudev02@gmail.com and \\ riddhi@iith.ac.in
}

\begin{abstract}
Incorporation of channel network information in streamflow modelling is a well-accepted scientific practice now. In particular, channel network morphology based instantaneous unit hydrographs (IUHs) are widely used for modelling of flood response. However, very few attempts have been made so far to use channel networks for modelling total flow, not just flood flow. In this study, total flow is partitioned into pure surface flow (PSF) and mixed surface-subsurface flow (MSSF), which are then modelled separately by constructing channel network morphology based IUHs. For modelling total flow, the combined IUH is then obtained by introducing a splitting parameter that represents the relative proportions of PSF and MSSF. We compare the performance of the proposed geomorphology based routing structure and a variant with a commonly used routing structure - two linear reservoirs in parallel. The three routing structures are then integrated with a wellknown water balance model to perform continuous streamflow modeling. We perform inter-model comparison quantitatively by considering eight perfor-
\end{abstract}


mance metrics within a multi-objective framework as well as qualitatively by observing the simulated storage-discharge relationships. By performing the inter-model comparison for 71 catchments across the US, we find that the geomorphology based models perform better than the linear model for low flow related metrics. They are also better at capturing non-linear and dynamic relationship between catchment water storage and discharge. The geomorphology based models perform particularly well in northeastern and midwestern US, while no such region of dominance emerges for the linear routing based model. Results also indicate the possibility of using the proposed models to capture the dominant flow generation processes in a basin. Keywords: Channel network, pure surface flow, mixed surface-subsurface flow, linear reservoirs, inter-model comparison, storage-discharge relationship

\section{1. Introduction}

2 Natural river basins store precipitated water and release it in the form of 3 streamflow while losing some amount through evapotranspiration and deep 
4 groundwater percolation. Streamflow response to precipitation is commonly 5 known as hydrologic response. Accurate modeling of hydrologic response is 6 relevant for a number of purposes, for e.g., efficient water resources manage7 ment and better preparedness for disasters like floods and droughts. Generally, the rainfall time series is first converted into effective rainfall time series (effective rainfall is the part of rainfall that ultimately transforms into streamflow) with the help of a water balance model. Then a routing function is used for transforming the effective rainfall time series into streamflow time series by accounting for mechanisms that transport water particles from various parts of the catchment to the outlet. Hydrologic response modeling by routing effective rainfall to the basin outlet is the focus of this study.

The practice of hydrologic response modeling is one of the oldest subjects in hydrology, and a variety of approaches can be found in the literature [e.g., 2]. Approaches to hydrologic response modelling can be broadly categorized as databased, conceptual, and physically based [73]. Data based model structures are based on observed data alone without any prior conceptualization of dominant processes. Physically based models attempt to build models from established first principles, such as conservation of mass, momentum and energy in saturated or unsaturated media. Conceptual models fall in the region between these two; they rely on observed data for their calibration and also invoke hydrologist's understanding of the dominant hydrologic processes in the watershed. Owing to their computational efficiency as compared to physically-based models, they are widely used for various practical applications.

One of the notable contributions in conceptual hydrologic modelling was 
done by Sherman [65], who introduced the concept of unit hydrograph, defined as the hydrologic response of the basin to a unit volume of effective rainfall. Often, it is mathematically convenient to obtain the unit hydrograph for an instantaneous effective rainfall input, which is also called as instantaneous unit hydrograph (IUH) [38]. The earliest IUH based hydrologic response modeling approaches were empirical or black-box type [e.g., 67; 19]. The limitation of a black-box type modeling approach is that it cannot be related to catchment physics, hence its applicability to ungauged regions is questionable. Therefore, many efforts in the past have been made to incorporate physical processes in constructing unit hydrographs $[28 ; 55 ; 54 ; 21 ; 33 ; 52]$. In fact it has become a standard practice to incorporate channel network information in IUH formulation, particularly after the pioneering works by Kirby [28] and Rodriguez-Iturbe et al. [55]. Such an IUH is known as geomorphological unit hydrograph (GIUH).

The applicability of a GIUH based model, however, is generally limited to flood response modeling, although the broad framework of GIUH can be utilized to also model drought flows or recession flows [62]. Recent studies show that active drainage network $(\mathrm{ADN})$ dynamics can explain hydrological response characteristics during recession periods $[3 ; 37 ; 6]$. This study puts forward a unified unit hydrograph based routing structure by: i) adopting a flow-path based flow partitioning scheme, and ii) proposing a channel network morphology based IUH for total flow modelling by combining the GIUH formulation with an ADN dynamics based recession flow model.

We test the channel network morphology based routing structure and its variant against a routing structure comprising of two linear reservoirs in 
parallel, which is frequently used for streamflow modelling [e.g., 1]. A well known water balance model is used to generate effective rainfall time series for each routing model structure. Inter-model comparison is performed using statistically and ecologically relevant metrics as well as qualitative measures such as ability of the models to reproduce the observed dynamic storagedischarge relationship. In order to understand how the model structures vary across hydro-climatic gradients, our inter-model comparison exercise is performed on 71 catchments across the US with a significant gradient in their climatic, geomorphologic, and geologic settings.

\section{Flow partitioning and a channel network morphology based IUH}

Water particles falling on a basin in the form of rain or snow pass through various flow paths and may exit the basin through its outlet. The time spent by an individual particle in the basin depends on the particular path it follows. A water particle following a surface flow path may require much less time to reach the basin outlet compared to a water particle that follows a subsurface flow path. The other feature about subsurface flow is that rain water may undergo a complex interaction with existing water stored in the subsurface domain [e.g., 7]. Hence, subsurface flow is a distinct and complex phenomenon, and it needs to be treated differently from surface flow in a modeling framework.

Modelling of hydrological response thus requires understanding of how water is redistributed among different flow paths and how the channel network morphology can help in developing conceptual models [57;21;3;18]. Early hydrological models, based largely on the work of Horton [23], par- 
titioned total flow into two components: fast surface flow or surface flow, dominating during floods, and and slow subsurface flow, dominating during recession periods. However, it is recognized now that flood response can also be caused by fast subsurface flow [e.g., 2]. Thus, we need an alternative conceptual framework to route different types of flow while considering the fast response of subsurface flow. In this study, geomorphological approaches are followed to model total flow by partitioning it into two distinct types: one that accounts for pure surface flow and the other that accounts for mixed surface-subsurface flow. This conceptualization is discussed next.

\subsection{Pure surface flow}

Pure surface flow (PSF) occurs when a water particle falling on a basin never enters into the subsurface domain. Direction of PSF at any point therefore will be determined by the steepest topographic gradient. Once a water particle falls on a hillslope, it will start moving towards the nearby stream (Figure 1a). One of the earliest conceptualizations of PSF was carried out by Imbeaux [25], who proposed a method to model surface flow of a basin by using its planar structure, popularly known as the method of time-area diagram [58]. Essentially, this method divides a basin into zones according to time taken by water particles to reach the basin outlet. It is generally assumed that the flow speed of water particles following surface flow paths is constant everywhere in a basin, which is quite reasonable [32]. That means, a water particle following a pure surface flow path of length $x$ will require time $x / V_{s}$ to reach the basin outlet, where $V_{s}$ is the speed of the water particle. Thus, at a particular time, PSF response will be determined by the number of sites contributing flow at the basin outlet. Mathematically, the IUH for 
PSF (PSFIUH) for the basin can be written as:

$$
u_{s}(t)=P\left(x=V_{s} \cdot t\right)
$$

where $P\left(x=V_{s} \cdot t\right)$ is the probability of a random point in the watershed with distance to the outlet $x$ being equal to $V_{s} \cdot t$. If we define PSF domain for a stream reach as the hillslopes from which it is receiving PSF directly, we can see that the channel reaches PSF domain will cover the adjoining hillslopes (Figure 1a). Now if one assumes drainage density to be constant in the watershed [60] and travel time of a water particle in the hillslope to be significantly shorter than its travel time in the channel network (valid for medium-to-large sized catchments, see [14]), then $P\left(x=V_{s} \cdot t\right)$ can be defined as the probability of a random point in the channel network with distance to the outlet $x$ being equal to $V_{s} \cdot t$, which is also known as the network width function [see 28; 54; 52]. Figure 2a shows PSFIUH for a sample basin.

\subsection{Mixed surface-subsurface flow}

Hydrologic response due to PSF can be observed during flood periods only and is intense and short lived. On the other hand, subsurface flow can occur at any point of time. Flow processes in a subsurface system are far more complex. Water particles falling on a basin may infiltrate into the hillslopes following hydraulic gradients and later exfiltrate along the stream channels from where they will travel in the stream network (surface flow) in downstream direction to ultimately reach the outlet of the basin. Therefore, if the subsurface system is involved, we will observe mixed surface-subsurface flow (MSSF). A water particle entering into the subsurface system may follow a local (short) flow path to reach the nearest stream channel. It may also 
follow a regional (long) flow path to reach a higher order stream by crossing one or more topographic highs and lows [71] (see Figure 1b). So unlike the case of PSF, a water particle can choose multiple MSSF paths.

We define here MSSF domain for a stream reach as the parts of the basin from which infiltrated water will ultimately exfiltrate into the stream reach. It can be understood that the MSSF domain for the stream reach will be much larger compared to its PSF domain, as water particles can find subsurface flow paths to exfiltrate into the stream reach from many other parts of the watershed situated at higher elevation (Figure 1b). This is why a higher order stream reach will have a larger MSSF domain when compared to a lower order stream reach. Thus, a higher order stream reach will likely contribute more MSSF at the basin outlet [45;4] and its contribution will last for a longer duration [5]. This phenomenon is taken into account in the conceptual framework proposed by Biswal and Marani [3] that allows the active portion of a drainage network (ADN) to shrink during dry (recession) periods and grow during wet periods. In particular, they assumed that flow generation per unit $\operatorname{ADN}$ length $(q)$ and the speed at which $\operatorname{ADN}$ heads move downstream $\left(V_{d}\right)$ remain constant for a recession period. Thus, this model implicitly takes into account the systematic spatial variation of MSSF contribution.

Apart from the fact the the assumptions above are questionable [e.g., 59], a major limitation of the model is that it ignores the travel time of a water particle in the channel network. A channel reach with distance to farthest source $l$, according to this model, will contribute from time $t=$ 0 to $l / V_{d}$. To address this issue, here we consider that a channel reach 
starts contributing MSSF at the basin outlet at time $t=x / V_{s}$ ends at $t=$ $x / V_{s}+l / V_{d}$. Mathematically, MSSF contribution from the channel reach at the outlet is: $q \Delta l \cdot\left[H\left(t-x / V_{s}\right)-H\left(t-x / V_{s}-l / V_{d}\right)\right.$, where $H(-)$ is the Heaviside function. Now the IUH for MSSF (MSSFIUH) for the catchment can be expressed as:

$$
u_{m}(t)=P\left[H\left(t-x / V_{s}\right)-H\left(t-x / V_{s}-l / V_{d}\right)=1\right]
$$

where $P\left[H\left(t-x / V_{s}\right)-H\left(t-x / V_{s}-l / V_{d}\right)=1\right]$ is the probability of a random channel reach contributing at time $t$. MSSFIUH for the sample basin is shown in Figure 2b. Note that the assumptions of MSSFIUH formulation indicate that the recession event is complete (i.e., discharge finally approaches zero). In real cases, most recession events are incomplete. Therefore, application of MSSFIUH for continuous streamflow simulation is based on the assumption that MSSF process satisfy the linearity assumption, which is essential any for unit hydrograph formulation.

\subsection{Construction of a channel network morphology based hydrologic response} model

To obtain the IUH for a basin that simulates total flow, we need to know the relative proportions of effective rainfall that transforms into PSF and MSSF. Let's assume that $\alpha$ is the ratio of the effective rainfall volume routed as PSF to the total effective rainfall volume. The combined IUH can then be given as:

$$
u(t)=\alpha \cdot u_{s}(t)+(1-\alpha) \cdot u_{m}(t)
$$

Eq. (3) constitutes a geomorphological hydrologic response model (GHRM) capable of simulating both flood flows and recession flows. Once we obtain 
the effective rainfall time series for a basin, we can obtain the discharge time series for the basin by following the principle of convolution. One may wonder here how GHRM performs in catchments where pure surface flow (Hortonian overland flow) is absent or, in other words, in MSSF dominated catchments. This phenomenon typically happens in humid-forested regions [2]. To address this issue, we also consider a model formulation that routes total flow using MSSFIUH alone, which can be considered as a variant of GHRM with the splitting parameter $\alpha=0$ (GHRM-NS). Figure 2c shows the GHRM for a sample basin by setting $\alpha=0.25$. Detail procedure to construct GHRM is given in Appendix A.

\section{Factors influencing GHRM}

This section concerns about the sensitivity of the model's performance to the parameters considered in this study.

\subsection{The effect of the velocity parameters $V_{s}$ and $V_{d}$}

The shape of PSFIUH is determined only by the parameter $V_{s}$, the average surface-flow velocity of water particles (Figure 3a). On the other hand, the shape of MSSFIUH is influenced by both $V_{s}$ and $V_{d}$ (Figure 3b). Higher values of $V_{s}$ produces PSFIUHs with shorter time spans and higher peaks. In other words, a basin will drain more quickly if the surface flow velocity is higher, and vice versa. Similarly, higher values of $V_{s}$ produce MSSFIUHs with higher peaks. However, the tale of MSSFIUH is dependent on the parameter $V_{d}$. The parameter $V_{d}$, on the other hand controls the tale of MSSFIUH, but not its rising limb (Figure 3c). 


\subsection{The effect of the splitting parameter $\alpha$}

The average surface velocity $V_{s}$ is generally much higher compared to $V_{d}$.

Because of this, PSFIUHs will occur for a much shorter duration compared to MSSFIUH. Therefore, if $\alpha$ is higher, the combined IUH will have a higher peak and the ordinates of the tale will be of lower value. However, the total flow duration will remain unchanged as it will be controlled by $V_{s}$ and $V_{d}$. Figure 4 shows GHRMs for different values of $\alpha$ keeping all other parameters constant.

The above observations above are quite generic. The analysis was performed for several other watersheds from the database (see supplementary material) and similar results were obtained. Note that there are other factors that can affect the model's performance, although their influences are not significant (see Appendix B).

\section{Testing the proposed model: comparing it with an existing hy- drologic response model in a multi-objective framework}

Each rainfall-runoff model should be considered as an independent hypothesis of the catchment processes and multiple such hypotheses should preferably be tested [9] . Furthermore, recent studies also suggest a modular approach to model development and testing that separates different runoff processes: effective rainfall (ER) generation, recharge, routing, etc. Here, we design such an experiment to compare the proposed GHRM and GHRM-NS routines with a liner routing module that is composed of two parallel linear reservoirs with relatively small and large mean residence times that are intended to represent quick and slow flow, respectively. Each flow type is then 
routed through the reservoir with residence time parameters $K_{q}$ [days], for quick flow, and $K_{s}$ [days], for slow flow. In order to compare these routing structures, we combine them with an effective rainfall (ER) generation scheme that comprises of a snow module followed by a bucket based ER generation mechanism (Appendix C, Figure 5). The total ER is divided into slow and quick components based on a split parameter, $\alpha$ (here, ratio of quick flow to total flow). In order to ensure that only the routing components are tested, we use the same ER generation component for all three models.

Concerns regarding the appropriateness of simple conceptualizations of complex watershed behavior have been raised since long. Thus, it is important to assess whether a model produces the right results for the right reasons [29]. Typical assessment strategies focus on lumped statistical performance measures that may fail to capture all aspects of dynamic watershed response $[24 ; 48]$. But models continue to be judged based on their ability to reproduce lumped performance measures as opposed to detailed assessment of their ability to capture the dynamic hydrologic response. The presence of parameter interactions and inability to identify optimal values for all parameters (termed as unidentifiability) further complicates the interpretation of calibrated parameter values [2]. Altogether, these challenges make it difficult to assess the representativeness of a calibrated model structure using statistical performance measures alone. Thus, we need frameworks that test model performance in a more comprehensive manner.

We frame our inter-model comparison using two guiding principles. First, we expand the range of performance measures to include both statistical and ecologically relevant criteria of model assessment. To this end, we employ 
multiple criteria to assess model structures and identify the Pareto optimal sets. Pareto optimal sets are those parameter sets that perform superior to all other parameter sets and are considered equivalent to each other in a multi-objective sense $[20 ; 74]$. Second, we assess the routing structures on their ability to represent the observed dynamic storage discharge relationship in the catchment. This is motivated from the idea that qualitative evaluation can also be useful when identifying suitability of model structures [63;2].

The inter-model comparison consists of four main steps (Figure 6). We begin by generating 10,000 randomly sampled parameter sets from a uniform distribution for the ER generation and the routing components separately (Appendix C). The a priori ranges for the parameters are given in Table 1. Then, the parameters of the ER generation component are combined with the corresponding routing parameters to generate the full parameter set for each of the three hydrologic model structures. As the same set of soil moisture accounting parameters is used for all three routing structures, the ER time series passed to each routing scheme is the same in our framework. Following this, the complete parameter sets are used to simulate streamflow for each watershed and performance metrics are calculated based on observed streamflow. Eight performance metrics are employed: Nash-Sutcliffe efficiency, volumetric bias and six ecologically relevant indicators (Appendix D). Finally, the performance of the parameter sets w.r.t. to all performance measures (see Table 2) across the three models are compared to identify Pareto optimal parameter sets (Appendix E). The models are then compared based on their ability to contribute to the Pareto approximate front and other metrics. 


\section{Study area and data sources}

We test our methodology across 78 watersheds in the US. These watersheds are selected from the MOPEX data set satisfying two criterion: they are classified as reference watersheds, and they provide a minimum of 10 years of overlapping climate data. The MOPEX dataset provides daily time series of streamflow, precipitation, average temperature, maximum temperature, and minimum temperature [15] (Table S1). Hargreaves equation is used to estimate the potential evapotranspiration from temperature time series [22]. Watershed characteristics are obtained from the Falcone dataset [16]. For each watershed, geomorphic information is obtained from the digital elevation model following the method described in Appendix A.

Among the 78 watersheds, we found that seven watersheds have runoff ratios less than 0.1, these are removed from further analysis. The remaining watersheds represent significant variability in hydro-climate with runoff ratios and aridity index ranging from $0.13-0.83$, and $0.39-3.41$, respectively, which were computed using MOPEX data. The computations Area of the watersheds ranges from 67 to $6675 \mathrm{~km}^{2}$ [16]. Baseflow index ranges from 11.21 to $78.40 \%$ [16]. Percentage of land use classified as urban, agriculture, and forests ranges between 0.00-9.64\%, 0.00-89.93\% and 1.91-96.98\%, respectively [16]. Topographic wetness index varies between 9.25-14.34.

\section{Results}

We present the results of the inter-model comparison in three sections. In Section 6.1, we test the performance of models based on their relative contribution to the Pareto approximate front. We examine the spatial variability 
of these contributions across the US to identify regions of dominance of each model structure. Next, in Section 6.2, we compare the Pareto approximate sets contributed by each model in terms of statistical and ecologically relevant performance metrics. We end our model comparison in Section 6.3 where we assess the ability of each routing scheme to capture a key element of the hydrologic response behavior - the dynamic storage discharge relationship during recession periods.

\subsection{Contribution of models to the Pareto approximate fronts}

We identify the Pareto approximate front using epsilon based non-dominated sorting of model-parameter set combinations using eight performance metrics across three model structures (for details, see Appendix E). The Pareto approximate sets obtained across 71 watersheds ranged between 32 to 1008 sets per 30,000 model-parameter set combinations. We found that the Pareto approximate sets adequately capture the observed hydrograph for most watersheds. We show this by plotting the envelope of simulated streamflows from the Pareto approximate sets contributed by each model structure (Figure $\mathrm{S} 1)$.

One way to judge the suitability of a model structure for a watershed is by testing the contribution of each model to the Pareto approximate front. If a model structure occupies a large region of the Pareto approximate front, it suggests greater representativeness of the model structure for the watershed as it is able to simulate good performance over a larger number of performance metrics. We found that there was no watershed for which a single model structure dominated the front. The relative contribution to the Pareto approximate front varied between 0-81.7\%, 2.3-81.2\%, and 0-88.7\%, 
for Linear, GHRM, and GHRM-NS, respectively. On visualizing the spatial distribution of the relative contributions, we find distinct spatial patterns for GHRM and GHRM-NS (Figure 7). GHRM-NS dominates in the northeastern US, while the GHRM dominates in parts of middle-eastern US. We did not find any region where the linear routing structure dominates the Pareto approximate front. We also did not find any model structure dominating in the western US. This is most likely due to sparsity of watersheds representing that region in our analysis.

The distinct spatial distribution of model performance quantified in terms of relative contribution to the Pareto approximate front indicates that catchment properties may play a role in determining appropriateness of the three model structures for simulating runoff in the eastern US. We explored this further by estimating the correlation between the contribution to Pareto approximate front and catchment properties across the 71 watersheds. These properties include geologic, drainage, topographic, and land use characteristics (Table S2). We further visually inspected all significant correlations (p-values $<0.01)$ and neglected characteristics with extreme values affecting the correlation estimates. We found 13,8 , and 0 characteristics that showed significant correlation with percentage contribution to the Pareto approximate front for Linear, GHRM, and GHRM-NS structures, respectively (Figures S2 and S3). Of note is the strong linear correlation of 0.42 $(-0.40)$ between the baseflow index and percentage contribution to the Pareto approximate set for the Linear (GHRM) structure. Several soil properties also show significant correlation for the Linear and GHRM structures. An interesting pattern that emerges from the correlation analysis is that gen- 
erally the Linear and GHRM structures show opposite correlation patterns, i.e., when one is positively correlated with a property, the other is negatively correlated.

\subsection{Performance in statistical and ecologically based metrics}

We now test the performance of each model structure across the eight performance metrics. For each watershed, the performance in a particular metric will vary across the Pareto approximate sets. We assess the median and interquartile range of the performance measure across the Pareto approximate sets contributed by each model. First, the performance for each model is assessed across all watersheds and then for each watershed individually.

The median and interquartile ranges of performance metric for each model across 71 watersheds are listed in Table 3 . The median performance in NSE across the three models varies between 0.41-0.52 with less than $20 \%$ median volumetric bias. We find some performance degradation for ecologically relevant metrics for all three model structures. GHRM shows lowest values of median bias for minimum April flow, maximum October flow, and high flow pulse count. GHRM-NS shows lowest values of median bias for low flow pulse count and low flow pulse duration. GHRM and GHRM-NS perform similarly well in simulating low flow pulse count (27\% and $25 \%$ median bias), with the Linear structure performing the worst with $43 \%$ median bias. All three structures perform well for high flow pulse count with median biases around 20\%. Low flow pulse duration was the hardest to simulate for all three model structures. The Linear and GHRM structure showed similar performance in this metric while the lowest median bias was observed for the GHRM-NS structure. The Linear structure emerged as the overall best 
structure only for simulating high flow pulse duration.

We now analyze the performance across each metric for each watershed. The best NSE obtained across the Pareto approximate sets for each model and watershed is shown in Figure 8. We find that no model emerges as significantly better than the others in terms of $N S E$ performance. Moving ahead with other metrics, we show the median and interquartile range of bias in the remaining performance metrics for each model (Figure 9). Overall, we find more variation in performances across metrics than across models or watersheds. Metrics such as volumetric bias, minimum April flow, and high flow pulse count have relatively lower median and interquartile values of percentage bias for all watersheds. On the other hand, frequency and duration metrics of low flow have much higher biases. Figure 9 shows particularly poor performance of the Linear structure for low flow pulse count, 29 watersheds are observed to have more than $50 \%$ median bias. On the other hand, for GHRM and GHRM-NS, the median bias for this metric is greater than $50 \%$ for only 8 and 14 watersheds. Similarly for low flow duration metric, the Linear, GHRM, and GHRM-NS structures result in a median bias of greater than $50 \%$ for 26,23 , and 18 watersheds, respectively. Thus, there is an indication of performance improvement for GHRM and GHRM-NS model structures when simulating low flow frequency and duration related metrics.

\subsection{Dynamic storage-discharge relationship}

The ability of a model to meet lumped measures of performance may not be an adequate representation of its ability to represent the dominant physical processes in the watershed in the light of potential parameter interactions and identifiability issues. For example, parameters may try to compensate for any 
systematic error in observations to reduce the calibration error. Thus, a move towards assessments that allow us to test the capacity of model structures to simulate dynamic watershed response behavior is needed. Towards this goal, we identify a key dynamic property that a routing component should be able to reproduce - the dynamic flow discharge relationship:

$$
\frac{d Q}{d t}=f\left(Q_{a v e}\right)
$$

where $d Q / d t$ is the rate of change of streamflow $\left[\mathrm{mm} / d a y^{2}\right], Q_{a v e}[\mathrm{~mm} / d a y]$ is the average streamflow, and $f$ is a nonlinear function that varies event by event [8]. Note that we have computed $d Q / d t$ and $Q_{a v e}$ at daily time-step. Events are defined as parts of the hydrograph with continuously decreasing streamflow for at least seven days. In this section, we attempt to test the model structures on their ability to simulate this relationship. Note that it is common to assume that for a particular watershed $d Q / d t$ versus $Q_{\text {ave }}$ relationship is time-invariant. However, recent studies have revealed that the relationship changes across events significantly [3; 64]. Therefore, instead of lumped metrics of evaluation, we compare the recession behavior of model structures both quantitatively through lumped measures and qualitatively, through visualization.

We visualize the $d Q / d t$ versus $Q_{\text {ave }}$ relationship for the Pareto approximate sets with the best $N S E$ performance for all watersheds (Figure S4). To summarize the observed trends across all watersheds, we choose three representative watersheds in which the Linear, GHRM, and GHRM-NS structures dominate the Pareto approximate front, respectively (Figure 10). We find a distinct difference in the dynamic patterns of storage-discharge relationship between the Linear and GHRM/ GHRM-NS routing structures. In partic- 
ular, we find that that the combination of two linear stores with different time constants tends to produce a linear relationship between $d Q / d t$ and $Q_{\text {ave }}$, which appears non-linear in the log-log space. On the other hand, the observed relationship is generally linear in the $\log -\log$ space and a power law type in the real space. The GHRM and GHRM-NS structures generally simulate a linear relationship in $\log -\log$ space. Across all watersheds, the median (interquartile range) of the power law exponent in Brustaert and Neiber's formulation is 1.30 (1.10-1.70), 1.60 (1.30-1.80), 1.40 (1.10-1.80), for the Linear, GHRM, and GHRM-NS model structures, respectively. The observed median (interquartile range) across the watersheds is 1.60 (1.401.80). Therefore, overall, GHRM is closest to the observed data in terms of representing the nature of the non-linearity of the observed relationship.

Another difference between the recession curves simulated by the routing structures is that of the spread of modelled recession streamflow values along the $\mathrm{x}$-axis in the $\log$ - $\log$ space. All observed recession curves show significant spread in streamflow values in the log-log space. In contrast, this spread is generally lower for all three routing routines. The mean value of the ratio of the simulated to observed spread across all watersheds is $0.71,0.96$, and 0.79, for Linear, GHRM, and GHRM-NS, respectively. Again, we find that the GHRM structure is closet to observed spread, when assessed across all the watersheds.

\subsection{Parameter identifiability}

After assessing model performance in terms of statistical metrics, ecologically relevant metrics, and recession behavior, we turn our focus on the inference derived from the ranges parameters belonging to the Pareto ap- 
proximate sets. This aids in understanding the identifiability of parameters as well as their optimal ranges for each model structure. We estimate the identifiability of model parameters, a measure of whether or not eight performance metrics can identify unique regions in the parameter space that lead to optimality. We quantify this by estimating the Kolmogorov-Smirnof $(K S)$ statistic or the maximum distance between the cumulative density function $(\mathrm{CDF})$ of the Pareto approximate parameter sets and the uniform distribution (apriori assumption) [34]. The CDFs of the Pareto approximate sets are shown against the apriori distribution for each watershed-parameter combination in Figure S5. The KS statistic is calculated from these CDFs.

We find that our choice of eight evaluation metrics is able to reduce the apriori range of the soil moisture accounting parameters for all three model structures (Table 4 and Figure 11). However, parameters related to the snow module remain unidentifiable for all but a few watersheds. In general, the change of routing schemes does not substantially alter the identifiability of parameters governing ER generation. The median $K S$ statistics for ER parameters $b$ and $C_{\max }$ suggest that they are slightly more identifiable for GHRM-NS (Table 4). The parameters $K_{s}$ and $V_{d}$, controlling the recession limb for Linear and GHRM, respectively, are more identifiable than $V_{d}$ for GHRM-NS. However, the parameters governing flood peaks, $K_{q}$ and $V_{s}$ for Linear, GHRM, and GHRM-NS are equally identifiable. Overall, we find that the parameters of the routing component are most identifiable for GHRM.

The parameter $\alpha$ controlling the split between quick and slow flow in the Linear structure and partitioning of PSF and MSSF in the GHRM model structure plays a major role in deciding the dominant routing processes in 
the watershed. On visualizing the distribution of $\alpha$ across all watersheds, we find that it follows opposite patterns for the two model structures (Figure 12). The linear routing structure tends to transfer more ER into the fast reservoir, while the GHRM routing structure tends to route more ER through the MSSF flow paths. Thus, the linear structure suggests that more water particles take quick flow paths through the watershed, while the GHRM structure suggests that they generally will follow a mixed flow path passing through both surface and sub-surface. These are two very different conceptualizations but both seem to pass the statistical performance criteria.

\section{Discussion}

We propose a channel network based routing model capable of simulating flood flow as well as recession flow. We test it's performance by comparing it with well known a widely used linear reservoir model. Nourani et al. [42] in a comprehensive study compared Nash and Soil Conservation Service (SCS) models with three geomorphology based linear and non-linear routing structures. They reported that models based on watershed geomorphologic properties outperform those that do not. It should be noted that an extensive comparison of several types of routing structures was performed by Stoelzle et al. [69] who found that in general, parallel linear reservoirs perform well across a variety of watersheds except those with karstic hydro-geology, for which the nonlinear power law based relationship performs well. In our study, only one watershed had a limestone dominated geologic setting: USGS gage ID 08171300, with a 'stony colluvium on limestone' [16]. It is worth pointing out that the linear routing structures had the highest errors in volumetric 
bias for this watershed averaging at $66 \%$. However, the geomorphology based routing structures were able to achieve average errors of $36 \%$ and $47 \%$, for the GHRM and GHRM-NS structures, respectively.

One more way to identify the appropriate routing structure is to learn from observations. Kim et al. [27] propose such a method in which a suitable routing structure is identified from a large number of possible structures using observed data instead of conceptualization by the modeler. However, these routing structures limit themselves to flood predictions and cannot be applied to ungauged basins due to the reliance on observations. On the other hand, GHRM and GHRM-NS model structures may enable prediction in ungauged basins, if the parameters $V_{s}$ and $V_{d}$ can be regionalized or related to watershed's physiographic settings.

Our analysis suggests that a model's performance can be evaluated checking its ability to capture storage-discharge relationships. An important aspect about storage-discharge relationship is that it varies across events [3; $64 ; 5]$. Interestingly, the method of instantaneous unit hydrograph is inherently based on dynamic storage-discharge relationship. According to unit hydrograph theory, for $I$ volume of effective rainfall at time $t=0$ discharge will be given as $Q(t)=I \cdot u(t)$ and storage as $S(t)=\int_{t}^{\infty} Q(t) d t=I \cdot s(t)$, where $s(t)=\int_{t}^{\infty} u(t) \cdot d t$. It can be observed that there can be a unique relationship between storage and discharge only when $s(t) \propto u(t)$. When storage-discharge relationship is not linear, which is generally true $[8 ; 3 ; 72]$, the relationship will be event dependent. Note that storage-discharge analysis is generally done by analyzing $d Q / d-Q$ relationship [3]. The ability of the proposed model to capture dynamic storage-discharge relationship lends 
further support to the notion that channel network information can exploited for hydrological modelling. Interestingly, the linear reservoir model produces nonlinear and dynamic $d Q / d-Q$ response due to interaction between the two parallel reservoirs. However, its behavior is not realistic.

We observe that both GHRM and GHRM-NS dominated catchments form spatial clustering. Of particular interest is the dominance of GHRM-NS in parts of the north-eastern US, which are generally humid mountainous regions (Figure 7). This supports the notion that water particles follow a mixed surface subsurface flow path in such humid forested watersheds and no pure surface flow component is required to simulate the observed hydrograph. This conceptualization is consistent with the claim that surface flow rarely occurs in such watersheds $[2 ; 46 ; 2]$. The proposed model thus seems to be capable of accurately representing hydrological flow processes, which further supports the notion that incorporation of channel network information in hydrological response modelling is physically meaningful.

There are some limitations of our framework that warrant further investigations. For example, the shape of IUH can vary significantly across rainfall-runoff events [35]. This phenomenon can be captured by allowing the parameters of proposed model to vary across events. For example, it is well known that $V_{s}$ depends on effective rainfall intensity [56]. Nevertheless a non-stationary IUH based model may be computationally inefficient, since it requires IUH construction for every time step separately. Therefore, if limited information and computational resources are available, a stationary IUH based model can be derived for a basin for hydrological response modelling. Furthermore, the ER generation mechanism used here is one out of several 
possibilities, and further analysis can reveal whether alternative ER components have a significant impact on the patterns of model performance. Next, despite our attempt to include a wide variety of watersheds, the number of watersheds selected by us are still relatively sparse and a model comparison across a larger number of watersheds and across several parts of the world may be required before generalizing these results.

Finally, we left out several other possible routing structures in our model comparison, such as, nonlinear storage-discharge structures, and structures that are spatially distributed. The main reason behind this choice was the general applicability of the parallel linear reservoir structure except for karstic geologies $[69 ; 17]$. Further studies are needed to test the applicability of the GHRM and GHRM-NS structures across a range of geologic settings.

\section{Conclusions}

The complex and dynamic nature of water flow paths in natural basins pose the challenge of modeling hydrological response on the basis of a purely mechanistic method. This prompts hydrologists to develop conceptual models for simulating hydrologic response. Hydrologists thus aim to construct a computationally efficient model with few parameters to calibrate. Using geomorphic information greatly aids this process [e.g., 57; 2]. Channel networks have helped in understanding patterns characterizing floods [33; 51] as well as droughts $[3 ; 37]$, indicating the possibility of using them in hydrological response modelling for various practical applications.

In this study, we present a parsimonious conceptual routing structure that uses watershed specific geomorphologic information. We compare this 
routing structure and its variant with a commonly used linear routing structure. All routing schemes use the same ER generation mechanisms to isolate the impact of routing structures on model performance. Our model comparison tests performance in terms of both statistically and ecologically relevant metrics within a multiple objective framework. This setup also allows us to test routing structures within a rainfall runoff modelling framework without the need for hydrograph separation or simplified ER generation.

The main strengths of this analysis lie in its comprehensive inter-model comparison exercise across a large number of watersheds. By testing our model structures within a multi-objective framework across a large number of basins, we found significant variability in dominating models structures across the continental US. We also found that geomorphology based structures perform similar to the linear routing structure in terms of $N S E$ and volumetric bias. However, they outperform the linear structure in simulating low flow frequency and duration metrics.

A key result of this analysis is the comparison of the $d Q / d t$ vs. $Q_{a v e}$ relationship during recession periods across the three routing structures. Overall, we found that the linear routing structure deviated most from observed $d Q / d t$ vs. $Q_{\text {ave }}$ relationship. We quantified these deviations using two metrics: the ability of a model-parameter set to capture the extent of its non-linearity. The linear reservoir model manages to produce non-linear and dynamical $d Q / d t-Q_{\text {ave }}$ by employing two linear reservoirs with different time constants. But, the observed relationships is generally better represented by the geomorphology based models. It should be also note that GHRM-NS appear to dominate in humid and mountainous regions where surface flow contribu- 
tion to streamflow is likely to be insignificant. This observation opens up the possibility of achieving more realistic depiction of dominating flow generation mechanisms in hydrologic response modelling.

\section{Acknowledgments}

The data sources for the data used in the study are listed in Section 5. In addition, Tables S1 and S2 provide a full list of United States Geological Survey (USGS) gage numbers for the watersheds used in the analysis, and catchment properties used from the Falcone dataset, respectively. The authors would like to acknowledge Jon Herman and Matthew Woodruff for providing the code for epsilon-based non dominated sorting (available at https://github.com/matthewjwoodruff/pareto.py). The authors would also like to thank the reviewers for their insightful comments.

\section{Appendices}

\section{A. GHRM from digital elevation model}

For delineation of channel networks, digital elevation models (DEMs) are widely used these days. Several methods (with relative merits and demerits) have been suggested for this purpose. Here D8 computer algorithm [43] is followed due to its simplicity. The DEM of a basin can be used to prepare the D8 flow direction map, and then from the D8 flow direction map, the D8 flow accumulation map can be obtained. The channel network for the basin can then be extracted by imposing a suitable flow accumulation threshold. 
For every channelized pixel, distance from the outlet $(x)$ can be computed by considering the flow direction map by moving along the steepest gradient till the outlet is reached. Similarly, for every channelized pixel the distance from the farthest source $(l)$ can be computed by moving in the upstream direction till the farthest channel head or source is reached. Note that while moving in upstream direction, often we encounter two upstream channel pixels leading to two upstream paths (a river network is typically a binary tree). It is generally recommended to choose the path with the upstream pixel having higher flow accumulation value [50].

Once we have the values of $x$ and $l$ for every channel pixel for a basin, we can obtain PSFIUH and MSSFIUH and construct GHRM (eq. (3)) for the catchment. For demonstration purpose Ohio Brush catchment (1002 sq km, OH, USGS gauge ID: 03237500) is considered here. The digital elevation model (30 m pixel size) for the basin was obtained from United States Geological Survey (http://gdex.cr.usgs.gov/gdex/). Note that ordinates of PSFIUH and MSSFIUH need to be computed at discrete time steps. If we choose a constant time step $\Delta t$, PSFIUH ordinate at time $t$ would be equal to the number of channel pixels for which $t-\Delta t / 2 \leq x / V_{s}<t+\Delta t / 2$ divided by the total number of channel pixels. However, MSSFIUH ordinate at time $t$ would be determined as number of channel pixels for which $x / V_{s} \leq t<x / V_{s}+l / V_{d}$ divided by the total number of channel pixels. 


\section{B. The effects of time step and flow accumulation threshold on PSFIUH and MSSFIUH}

\section{B.1. The effect of time step $\Delta t$}

For hydrologic routing, we generally need IUH ordinates for discrete time intervals. Therefore, the time-step $(\Delta t)$ at which computation is done may influence the shape of the IUH. This, however, has a benefit. It is assumed here that pure surface flow occurs with every water particle moving downstream at a constant speed $\left(V_{s}\right)$. A water particle starting from a point situated at a distance $x$ from the basin outlet will exactly take time $t=x / V_{s}$ to reach the basin outlet. That is, there is only advection type of flow. In reality, different water particles may assume different average flow velocities due to diffusion and other factors. Thus, two water particles starting their journey together from a point in the catchment may not reach the outlet at the same time. This issue can be addressed by solving the advection diffusion equation, which will yield a smoother hydrologic response curve [51; 14]. Of course, this means inclusion of an additional parameter (the dispersion coefficient) in the model. However, the diffusion effect can also be incorporated by selecting a larger time step. The probability of the two water particles reaching the outlet between time $t-\Delta t / 2$ and $t+\Delta t / 2$ will be higher for a larger $\Delta t$ (see Appendix A for details), due to which PSFIUH will be smoother for larger time steps (Figure 13a). The artificial introduction of diffusion is known as numerical diffusion [70]. This is desirable in our case, since hydrological modelling is usually done at at higher time step for which the response curve is expected to be smooth (Figure 13a). Note that in this study we perform discharge modelling at daily time step. Fig- 
ure 13b shows MSSFIUHs for different time steps considering that all other parameters remain unchanged. It can be observed that MSSFIUH is quite insensitive to the chosen time step for large time steps, although not during the early response period (Figure 13b).

\section{B.2. The choice of flow accumulation threshold}

Channel network extraction depends on the flow accumulation threshold. A lower value of flow accumulation threshold will produce a channel network with higher drainage density, and vice versa. It is observed that lower flow accumulation thresholds produce PSFIUHs that are relatively more rough. However, the curves obtained using different flow accumulation thresholds are not very different from each other (Figure 14a). MSSIUH too is found to be quite insensitive to the choice of flow accumulation threshold (Figure 14b). Insensitivity of PSFIUH and MSSFIUH to flow accumulation threshold suggests that they are influenced mainly by the branching patterns of stream network structure, not by the drainage density. However, MSSFIUH during high flow periods does display sensitivity to the choice of flow accumulation threshold 14b. For practical purposes, a suitable threshold, therefore, can be chosen (in this study, 100 pixels with a pixel size of $30 \mathrm{~m}$ ).

\section{The effective rainfall generation component}

We used the probability distributed model (PDM) [36] coupled with the degree-day method based snow module to generate effective rainfall (Figure 6). Precipitation enters the model through the snow module where the average daily temperature and the parameter representing threshold temperature for snow formation $\left(T_{t}\right)$ determine whether precipitation falls as snow 
or rain. Following this, the amount of snow melted is determined based on the average daily temperature and two additional model parameters using the following equation,

$$
M=D \times\left(T_{a v}-T_{b}\right)
$$

where, $M[\mathrm{~mm} /$ day $]$ is the melt at the end of every time step, $T_{a v}\left[{ }^{\circ} \mathrm{C}\right]$ is the average temperature for the day, $D\left[\mathrm{~mm} /\right.$ day $\left./{ }^{\circ} \mathrm{C}\right]$ is the degree day factor, and $T_{b}\left[{ }^{\circ} \mathrm{C}\right]$ is the parameter representing the base temperature above which melting takes place [13]. Following this, the melt and/or rainfall enters the soil moisture accounting module, where effective rainfall (ER) is generated based on a probability distribution of soil moisture stores. The distribution of stores depends upon two parameters: the shape parameter, $b$ and maximum height of the soil moisture stores, $C_{\max }[\mathrm{mm}]$. Together, these determine the maximum storage capacity of the catchment, $S_{\max }[\mathrm{mm}]$ as,

$$
S_{\max }=\frac{C_{\max }}{1+b}
$$

Actual evapotranspiration, $E T[\mathrm{~mm} / \mathrm{d}]$, is generated by scaling the potential evapotranspiration at a given time steps based on the currently available soil moisture. The ER is generated by following the fill and spill concept and is passed on to the three routing components.

\section{Metrics for model inter comparison}

\section{D.1. Statistical performance measures}

The often used the Nash Sutcliffe Efficiency (NSE) measure [40] and volumetric bias are used to represent the overall performance of the model- 
parameter combination. The NSE is estimate as,

$$
N S E=1-\frac{\sum_{t=1}^{T}\left(q_{s}(t)-q_{o}(t)\right)^{2}}{\sum_{t=1}^{T}\left(q_{o}(t)-\tilde{q}_{o}\right)^{2}},
$$

where $q_{s}$ is the simulated flow, $q_{o}$ is the observed flow at time $t, \tilde{q}_{o}$ is the mean of the observed flow, and $T$ is the time period of simulation. The volumetric bias is calculated as,

$$
\% \text { Bias }=\frac{\sum_{t=1}^{T}\left(q_{s}(t)-q_{o}(t)\right)}{\sum_{t=1}^{T} q_{o}(t)} \times 100,
$$

where \%Bias is the volumetric bias expressed as a percentage of observed flows, and the remaining terms are defined before. In addition, we also perform a Box Cox transformation on the streamflow time series before calculating NSE to give equal weightage to low flows [31]. The box-cox transformation is achieved by,

$$
q_{\lambda}(t)=\left\{\begin{array}{l}
\frac{q(t)^{\lambda-1}}{\lambda}, \text { if } \lambda \neq 0 \\
\lambda, \text { otherwise }
\end{array}\right.
$$

,where $q_{\lambda}$ is the Box-Cox transformation of the flow, $q$ at time $t$. We use a lambda of 0.3 .

\section{D.2. Ecologically relevant flow metrics}

In addition to statistical measures of performance outlined before, we select six additional metrics that span a range of ecologically relevant characteristics for a stream. We note that a large number of possible indicators exist [44]. In order to guide indicator selection, we categorize the indicators into three categories: magnitude related, frequency related and duration related. We select two indicators from each category, one for high flows and 
another for low flows. Table 2 lists the definition of each indicator. For each indicator, the performance metric is quantified as the percentage bias between its observed and simulated value.

\section{E. Non dominated sorting procedure}

After estimating the eight performance measures (two statistical and six ecological) for each combination of model structure and parameter set, we need a mechanism to compare these with each other in a multi-objective sense. One way to do this is by performing a non-dominated sorting of performance measures across all model-parameter set combinations. Nondominated sorting identifies the Pareto optimal model-parameter set combinations, i.e., those combinations that are better than all other combinations in all performance measures, and non-dominated w.r.t to each other [68; 11]. If a parameter set is able to simulate all measures better than the rest, it will be the sole member of the Pareto optimal set. However, more often than not, increasing performance in one measure is likely to decrease performance in others, leading to conflicts. In such cases the Pareto optimal sets will represent the range of all possible compromises across the performance measures.

For each watershed, 30,000 model-parameter set combinations are sorted at the same time $(10,000$ parameters for each of the three models). Since recent studies have shown that non-dominated sorting without accounting for significance levels (epsilons) is likely to lead to meaningless tradeoffs [30], we use epsilon-based non-dominated sorting and set the level of significance of each measure [12]. We set an epsilon value of 0.1 for $N S E$ and $10 \%$ for 
all other measures that quantify bias. In this analysis, we chose to identify Pareto optimal sets by performing an epsilon based non-dominated sort on the randomly sampled parameter sets, without using any optimization algorithm to search the feasible space of model parameters. This is because we need to generate the same ER time series for each routing scheme to make a fair comparison. An optimization algorithm will have to jointly search the space of all parameter sets for the three hydrologic model structures to ensure that $\mathrm{ER}$ is the same across all models. Due to differences in the ranges of the routing parameters as well as the total number of parameters, this is currently not feasible computationally. Note also that unless the optimization problem is analytically tractable, the Pareto fronts obtained by optimization are also an approximation of the true front. We therefore refer to the Pareto front thus obtained as the Pareto approximate front.

\section{References}

[1] Blasone RS, Vrugt JA, Madsen H, Rosbjerg D, Robinson BA, Zyvoloski GA. Generalized likelihood uncertainty estimation (GLUE) using adaptive Markov Chain Monte Carlo sampling Advances in Water Resources. 2008; 31(4): 630-648.

[2] Beven KJ. Rainfall-runoff modelling: the primer. John Wiley \& Sons; 2011.

[3] Biswal B, Marani M. Geomorphological origin of recession curves. Geophysical Research Letters. 2010; 37(24).

[4] Biswal B, Nagesh Kumar D. A general geomorphological recession flow 
model for river basins. Water Resources Research. 2013; 49(8): 49004906.

[5] Biswal B, Kumar DN. What mainly controls recession flows in river basins? Advances in Water Resources. 2014; 65: 25-33.

[6] Biswal B, Kumar DN. Estimation of 'drainable' storage-A geomorphological approach. Advances in Water Resources. 2015; 77: 37-43.

[7] Botter G, Bertuzzo E, Rinaldo A. Transport in the hydrologic response: Travel time distributions, soil moisture dynamics, and the old water paradox. Water Resources Research. 2010; 46(3).

[8] Brutsaert W, Nieber JL. Regionalized drought flow hydrographs from a mature glaciated plateau. Water Resources Research. 1977; 13(3): $637-643$.

[9] Clark MP, Nijssen B, Lundquist JD, Kavetski D, Rupp DE, Woods RA, et al. A unified approach for process-based hydrologic modeling: 1 . Modeling concept. Water Resources Research. 2015;51(4):2498-2514.

[10] Coe MT, Costa MH, Howard EA. Simulating the surface waters of the Amazon River basin: impacts of new river geomorphic and flow parameterizations. Hydrological Processes. 2008;22(14):2542-2553.

[11] Deb K, Agrawal S, Pratap A, Meyarivan T. A fast elitist non-dominated sorting genetic algorithm for multi-objective optimization: NSGA-II. In: Parallel problem solving from nature PPSN VI. Springer; 2000. p. 849858. 
[12] Deb K, Mohan M, Mishra S. Evaluating the epsilon-Domination Based Multi-Objective Evolutionary Algorithm for a Quick Computation of Pareto-Optimal Solutions. Evolutionary computation. 2005;13(4):501525.

[13] DeWalle DR, Rango A. Principles of snow hydrology. Cambridge University Press; 2008.

[14] D'Odorico P, Rigon R. Hillslope and channel contributions to the hydrologic response. Water resources research. 2003; 39(5).

[15] Duan Q, Schaake J, Andreassian V, Franks S, Goteti G, Gupta H, et al. Model Parameter Estimation Experiment (MOPEX): An overview of science strategy and major results from the second and third workshops. Journal of Hydrology. 2006;320(1):3-17.

[16] Falcone JA, Carlisle DM, Wolock DM, Meador MR. GAGES: A stream gage database for evaluating natural and altered flow conditions in the conterminous United States: Ecological Archives E091-045. Ecology. 2010;91(2):621-621.

[17] Fenicia F, Kavetski D, Savenije HH, Pfister L. From spatially variable streamflow to distributed hydrological models: Analysis of key modeling decisions. Water Resources Research. 2016;.

[18] Ghosh DK, Wang D, Zhu T. On the transition of base flow recession from early stage to late stage. Advances in Water Resources. 2016; 88: 8-13. 
[19] Gray DM. Synthetic unit hydrographs for small watersheds. Journal of the Hydraulics Division. 1961; 87(4): 33-54.

[20] Gupta HV, Sorooshian S, Yapo PO. Toward improved calibration of hydrologic models: Multiple and noncommensurable measures of information. Water Resources Research. 1998;34(4):751-763.

[21] Gupta VK, Mantilla R, Troutman BM, Dawdy D, Krajewski WF. Generalizing a nonlinear geophysical flood theory to medium-sized river networks. Geophysical Research Letters. 2010; 37(11).

[22] Hargreaves G, Samani Z. Reference crop evapotranspiration from temperature. Applied engineering in agriculture. 1985;1(2):96-99.

[23] Horton RE. The role of infiltration in the hydrologic cycle. Eos, Transactions American Geophysical Union. 1933; 14(1): 446-460.

[24] Houghton-Carr H. Assessment criteria for simple conceptual daily rainfall-runoff models. Hydrological Sciences Journal. 1999;44(2):237261.

[25] Imbeaux E. La Durance: régime, crues et inondations. Ch. Dunod; 1892.

[26] Jakeman A, Littlewood I, Whitehead P. Computation of the instantaneous unit hydrograph and identifiable component flows with application to two small upland catchments. Journal of hydrology. 1990;117(14):275-300. 
[27] Kim DH, Georgakakos AP. Hydrologic routing using nonlinear cascaded reservoirs. Water Resources Research. 2014;50(8):7000-7019.

[28] Kirkby M. Tests of the random network model, and its application to basin hydrology. Earth Surface Processes. 1976;1(3):197-212.

[29] Klemeš V. Conceptualization and scale in hydrology. Journal of hydrology. $1983 ; 65(1): 1-23$.

[30] Kollat J, Reed P, Wagener T. When are multiobjective calibration trade-offs in hydrologic models meaningful? Water Resources Research. $2012 ; 48(3)$.

[31] Kottegoda NT, Rosso R. Probability, statistics, and reliability for civil and environmental engineers. 1997;.

[32] Leopold LB, Maddock Jr T. The hydraulic geometry of stream channels and some physiographic implications; 1953.

[33] Mantilla R, Troutman BM, Gupta VK. Testing statistical self-similarity in the topology of river networks. Journal of Geophysical Research: Earth Surface. 2010; 115(F3).

[34] Massey Jr FJ. The Kolmogorov-Smirnov test for goodness of fit. Journal of the American statistical Association. 1951;46(253):68-78.

[35] Minshall NE. Predicting storm runoff on small experimental watersheds. Journal of the Hydraulics Division. 1960; 86(8): 17-38.

[36] Moore R. The PDM rainfall-runoff model. Hydrology and Earth System Sciences. 2007;11(1):483-499. 
[37] Mutzner R, Bertuzzo E, Tarolli P, Weijs SV, Nicotina L, Ceola S, et al. Geomorphic signatures on Brutsaert base flow recession analysis. Water Resources Research. 2013; 49(9): 5462-5472.

[38] Nash J. The form of the instantaneous unit hydrograph;. International Association of Scientific Hydrology, Publ. 1957; 3: 114-21.

[39] Nash J. Systematic determination of unit hydrograph parameters. Journal of Geophysical Research. 1959;64(1):111-115.

[40] Nash JE, Sutcliffe JV. River flow forecasting through conceptual models part I-A discussion of principles. Journal of hydrology. 1970;10(3):282290.

[41] Nearing GS, Gupta HV. The quantity and quality of information in hydrologic models. Water Resources Research. 2015;51(1):524-538.

[42] Nourani V, Singh VP, Delafrouz H. Three geomorphological rainfallrunoff models based on the linear reservoir concept. Catena. 2009;76(3):206-214.

[43] O'Callaghan JF, Mark DM. The extraction of drainage networks from digital elevation data. Computer vision, graphics, and image processing. 1984; 28(3): 323-344.

[44] Olden JD, Poff N. Redundancy and the choice of hydrologic indices for characterizing streamflow regimes. River Research and Applications. 2003;19(2):101-121. 
[45] Ophori D, Tóth J. Relationships in regional groundwater discharge to streams: An analysis by numerical simulation. Journal of Hydrology. 1990; 119(1): 215-244.

[46] Pearce A, Stewart M, Sklash M. Storm runoff generation in humid headwater catchments: 1 . Where does the water come from? Water Resources Research. 1986;22(8):1263-1272.

[47] Reed JC, Bush CA. About the geologic map in the National Atlas of the United States of America. Citeseer; 2007.

[48] Reusser DE, Blume T, Schaefli B, Zehe E. Analysing the temporal dynamics of model performance for hydrological models. Hydrology and earth system sciences. 2009;13(EPFL-ARTICLE-162488):999-1018.

[49] Rikkert S. Improving model consistency and process realism in conceptual rainfall-runoff models. TU Delft, Delft University of Technology; 2015 .

[50] Rigon R, Rodriguez-Iturbe I, Maritan A, Giacometti A, Tarboton DG, Rinaldo A. On Hack's law. Water Resources Research. 1996; 32(11): $3367-3374$.

[51] Rigon R, D'Odorico P, Bertoldi G. The geomorphic structure of the runoff peak. Hydrology and Earth System Sciences. 2011; 15(6): 18531863.

[52] Rigon R, Bancheri M, Formetta G, de Lavenne A. The geomorphological unit hydrograph from a historical-critical perspective. Earth Surface Processes and Landforms. 2015; 
[53] Rinaldo A, Marani A, Rigon R. Geomorphological dispersion. Water Resources Research. 1991; 27(4): 513-525.

[54] Rinaldo A, Vogel GK, Rigon R, Rodriguez-Iturbe I. Can one gauge the shape of a basin? Water Resources Research. 1995; 31(4): 1119-1127.

[55] Rodríguez-Iturbe I, Valdes JB. The geomorphologic structure of hydrologic response. Water resources research. 1979; 15(6): 1409-1420.

[56] Rodríguez-Iturbe I, González-Sanabria M, Bras RL. A geomorphoclimatic theory of the instantaneous unit hydrograph. Water Resources Research. 1982; 18(4): 877-886.

[57] Rodríguez-Iturbe I, Rinaldo A. Fractal river basins: chance and selforganization. Cambridge University Press; 2001.

[58] Ross CN, et al. The calculation of flood discharges by the use of a time contour plan. Transactions of the Institution of Engineers, Australia. 1921; 2: 85 .

[59] Shaw, S. B. (2016). Investigating the linkage between streamflow recession rates and channel network contraction in a mesoscale catchment in New York state. Hydrological Processes, 30(3), 479-492. Investigating the linkage between streamflow recession rates and channel network contraction in a mesoscale catchment in New York state. Hydrological Processes. 2016; 30(3), 479-492.

[60] Shreve RL. Infinite topologically random channel networks. The Journal of Geology. 1967; 178-186. 
[61] Saeidifarzad B, Nourani V, Aalami MT, Chau KW. Multi-site calibration of linear reservoir based geomorphologic rainfall-runoff models. Water. 2014;6(9):2690-2716.

[62] Schaefli B, Nictina L, Imfeld C, Da Ronco P, Bertuzzo E, Rinaldo A. SEHR-ECHO v1. 0: a Spatially Explicit Hydrologic Response model for ecohydrologic applications Geoscientific Model Development. 2014; $7(6), 2733-2746$.

[63] Seibert J, McDonnell JJ. On the dialog between experimentalist and modeler in catchment hydrology: Use of soft data for multicriteria model calibration. Water Resources Research. 2002;38(11).

[64] Shaw SB, Riha SJ. Examining individual recession events instead of a data cloud: Using a modified interpretation of $\mathrm{dQ} / \mathrm{dt}-\mathrm{Q}$ streamflow recession in glaciated watersheds to better inform models of low flow. Journal of Hydrology. 2012; 434: 46-54.

[65] Sherman LK. Streamflow from Rainfall by the Unit Graph Method. Eng News Rec. 1932; 108: 501-505.

[66] Sivapalan M, Thompson S, Harman C, Basu N, Kumar P. Special Section: Approaches to Synthesis: Watersheds as Dynamic, Cascading, Hierarchical, Nonlinear Space-Time Filters. Overview of Special SectionW00J01 Water cycle dynamics in a changing environment: Improving predictability through synthesis (doi 10.1029/2011WR011377). Water Resources Research. 2011;47(10). 
[67] Snyder FF. Synthetic unit-graphs. Eos, Transactions American Geophysical Union. 1938; 19(1): 447-454.

[68] Srinivas N, Deb K. Muiltiobjective optimization using nondominated sorting in genetic algorithms. Evolutionary computation. 1994;2(3):221248.

[69] Stoelzle M, Weiler M, Stahl K, Morhard A, Schuetz T. Is there a superior conceptual groundwater model structure for baseflow simulation? Hydrological Processes. 2015;29(6):1301-1313.

[70] Thomas JW. Numerical partial differential equations: finite difference methods. vol. 22. Springer Science \& Business Media; 2013.

[71] Toth J. A theoretical analysis of groundwater flow in small drainage basins. Journal of geophysical research. 1963; 68(16): 4795-4812.

[72] Vogel RM, Lall U, Cai X, Rajagopalan B, Weiskel PK, Hooper RP, et al. Hydrology: The interdisciplinary science of water. Water Resources Research. 2015; 51(6): 4409-4430.

[73] Wagener T, Wheater HS, Gupta HV. Rainfall-runoff modelling in gauged and ungauged catchments. Imperial College Press, London, UK; 2004 .

[74] Yapo PO, Gupta HV, Sorooshian S. Multi-objective global optimization for hydrologic models. Journal of hydrology. 1998;204(1):83-97. 

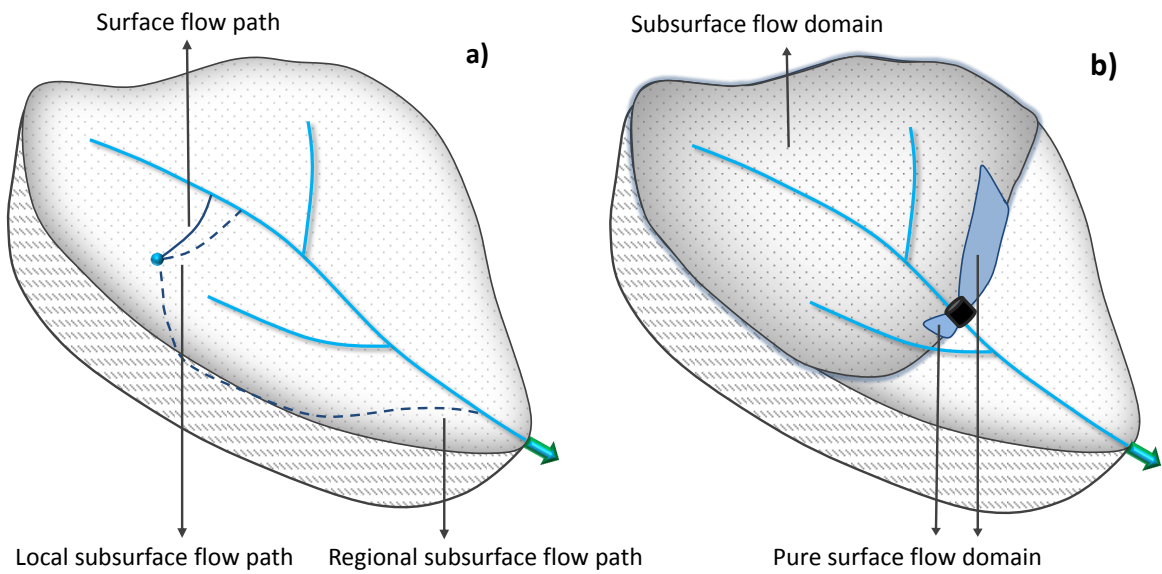

Figure 1: a) Pure surface flow (PSF) vs. mixed surface-subsurface flow (MSSF). PSF (solid dark-blue line) occurs in the direction of steepest gradient. In this type of flow, a water particle never enters into the subsurface domain. MSSF on the other hand occurs when a water particle follows a subsurface flow path (dotted dark-blue line) before exiting the basin through the outlet. It can follow a short (local) subsurface flow path or long (regional) subsurface flow path. b) The PSF domain of a channel reach (dark cylinder in the figure) will comprise of the adjoining hillslopes only. On the other hand the MSSF domain of the channel reach can be much larger due to the fact that water from a large of the basin can follow subsurface paths and exfiltrate into the channel reach. 

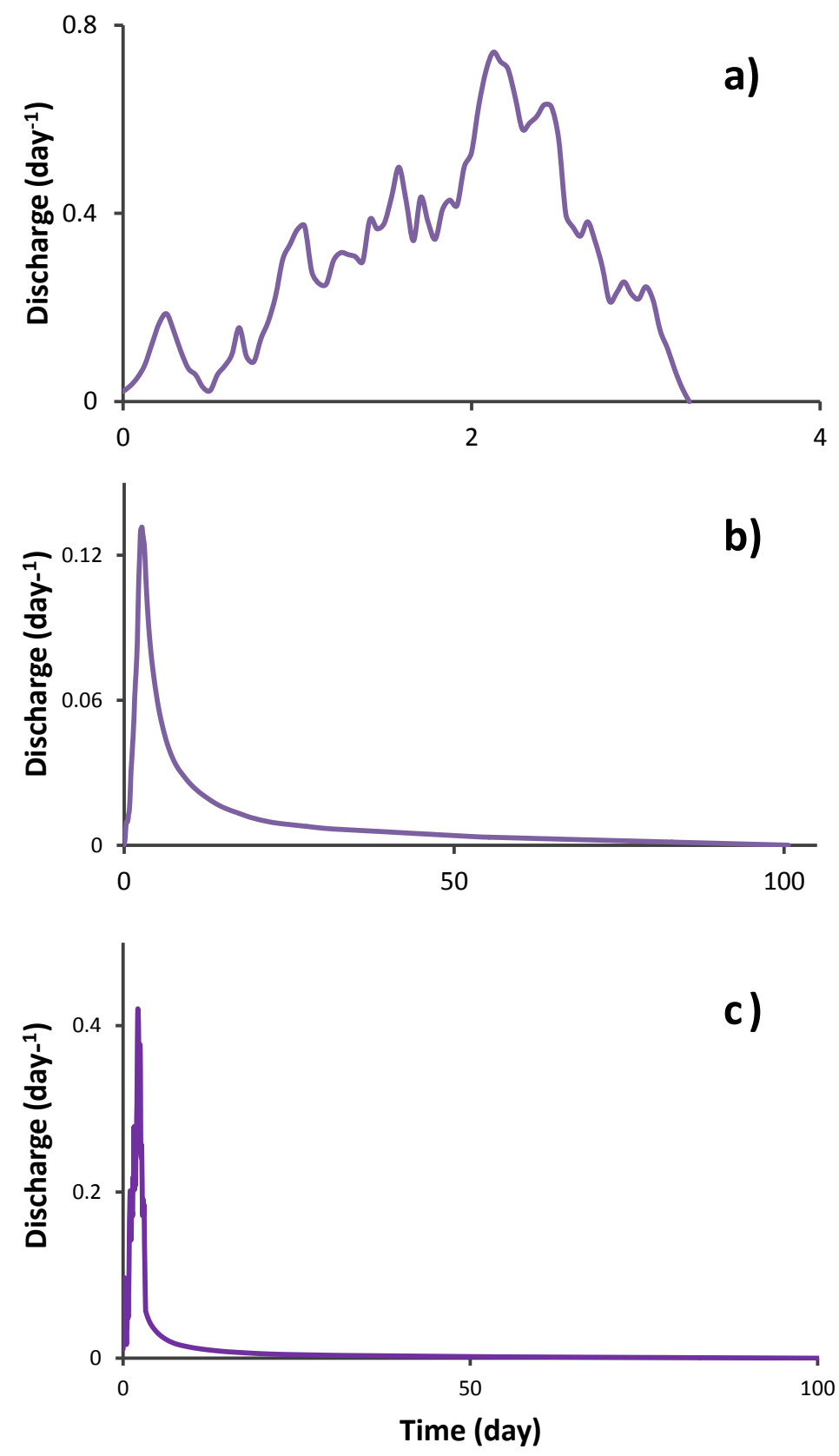

Figure 2: a) PSFIUH obtained for Ohio Brush catchment by setting $V_{s}=1 \mathrm{~km} / \mathrm{hr}$. b) MSSFIUH was obtained for the basin by setting $V_{d}=0.033 \mathrm{~km} / \mathrm{hr}$ ( $V_{s}$ is unchanged). c) GHRM is obtained for the basin by combining two IUHs and setting $\alpha$ at 0.25 . Note that since PSFIUH will have a much smaller5timescale (total duration of flow) compared to MSSFIUH, the beginning of the recession limb of GHRM is very steep. The channel network of the basin was obtained by putting a flow accumulation threshold equals to 100 pixels. 

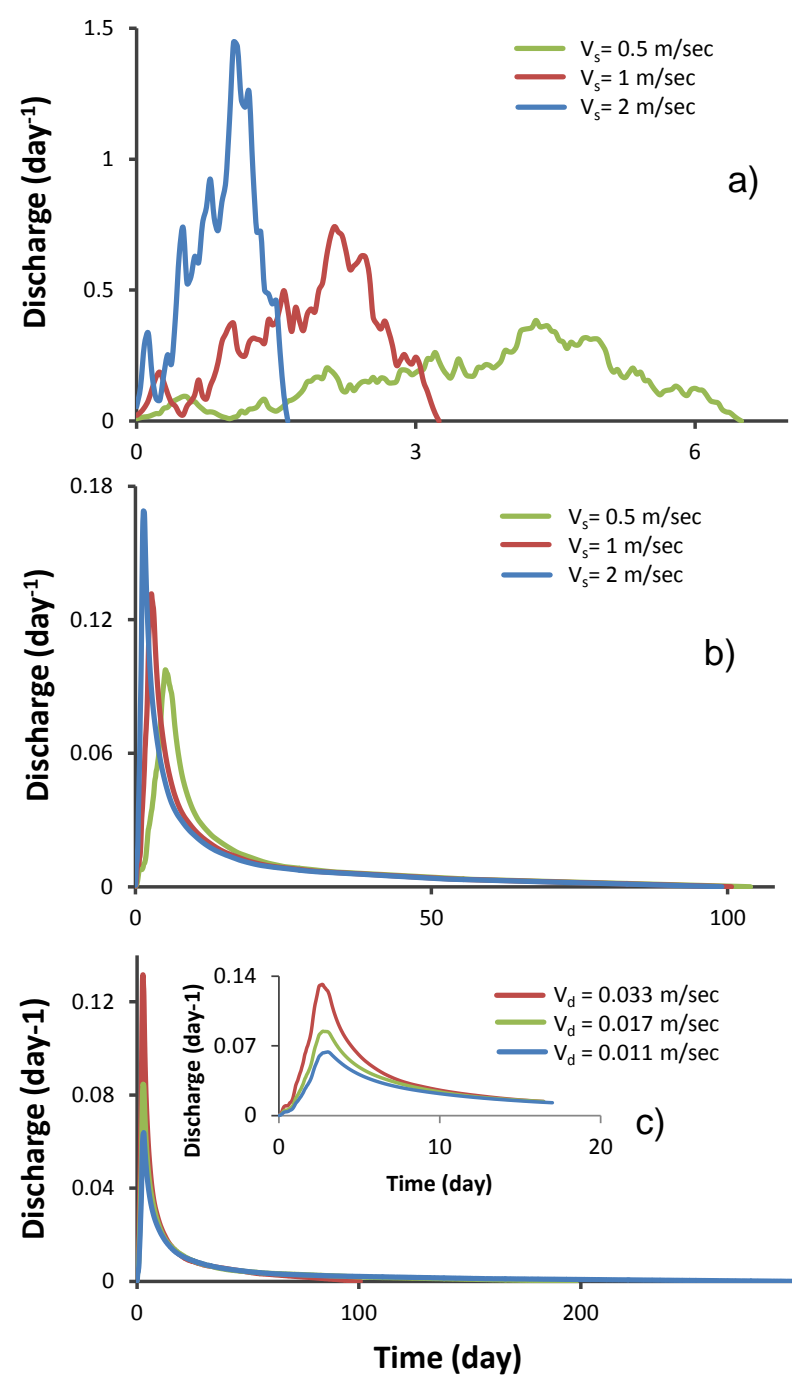

Figure 3: a) PSFIUH is significantly controlled by surface flow velocity $V_{s}$. Higher values of $V_{S}$ produce PSFIUHs with higher peaks and shorter time spans, and vice versa. b) $V_{s}$ similarly controls MSSFIUH, although its control is limited to the early parts only. Note that the length of MSSFIUH is quite independent of $V_{s}$, unlike the case of PSFIUH. $V_{d}$ in both the figures was fixed at $0.033 \mathrm{~km} / \mathrm{hr}$. c) The shape of MSSFIUH is mainly controlled by $V_{d}$, which represents the time period for which a channel pixel contributes flow. A higher $V_{d}$ generate MSSFIUH with shorter duration and higher peak, and vice versa. $V_{s}$ in this figure was fixed at 1 . For all the figures flow accumulation threshold was 100 pixels. 


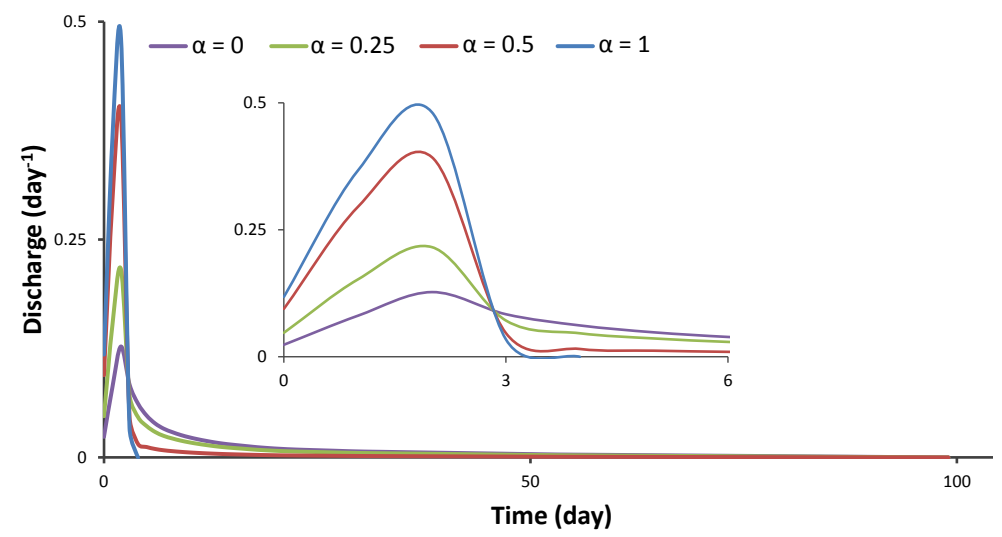

Figure 4: The combined IUH (GHRM) for different values of the splitting parameter $(\alpha)$, which is the fraction of total effective rainfall transforming into PSF. It can be noticed that the CIUH peak is higher for a higher value of $\alpha$, and vice versa. This is because $\alpha$ refers to PSF fraction and PSF is mote intense occurring during flood periods only. $V_{s}$, $V_{d}$ and flow accumulation threshold were fixed at $1 \mathrm{~km} / \mathrm{hr} 0.033 \mathrm{~km} / \mathrm{hr}$ and 100 pixels, respectively. 


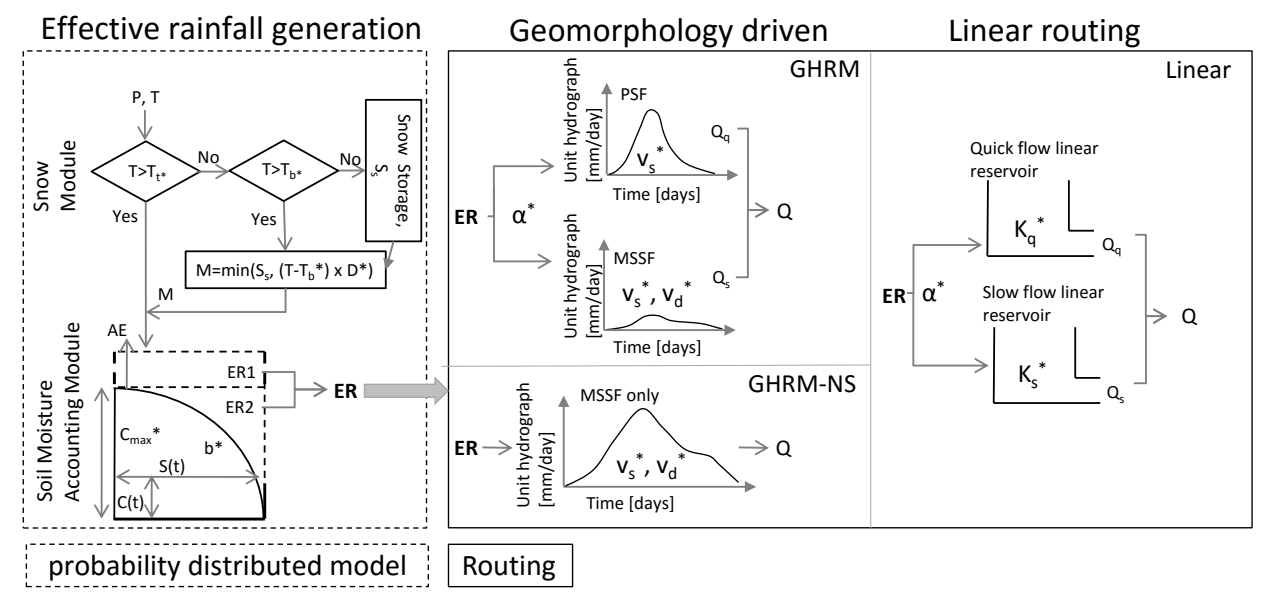

Figure 5: The design of computational experiment for inter-model comparison. Randomly sampled parameter sets for the ER generation component are combined with corresponding sets from three different routing schemes-Linear, GHRM, and GHRM-NS. The resultant sets are used to simulate hydrographs, which are then compared with the observed hydrograph using several statistical and ecologically relevant performance measures. This multi-objective comparison framework identifies the Pareto approximate sets of parameters across all model structures. PDM: probability distributed model, PSF: pure surface flow, MSSF: mixed surface subsurface flow, $\Theta$ : parameter sets. 


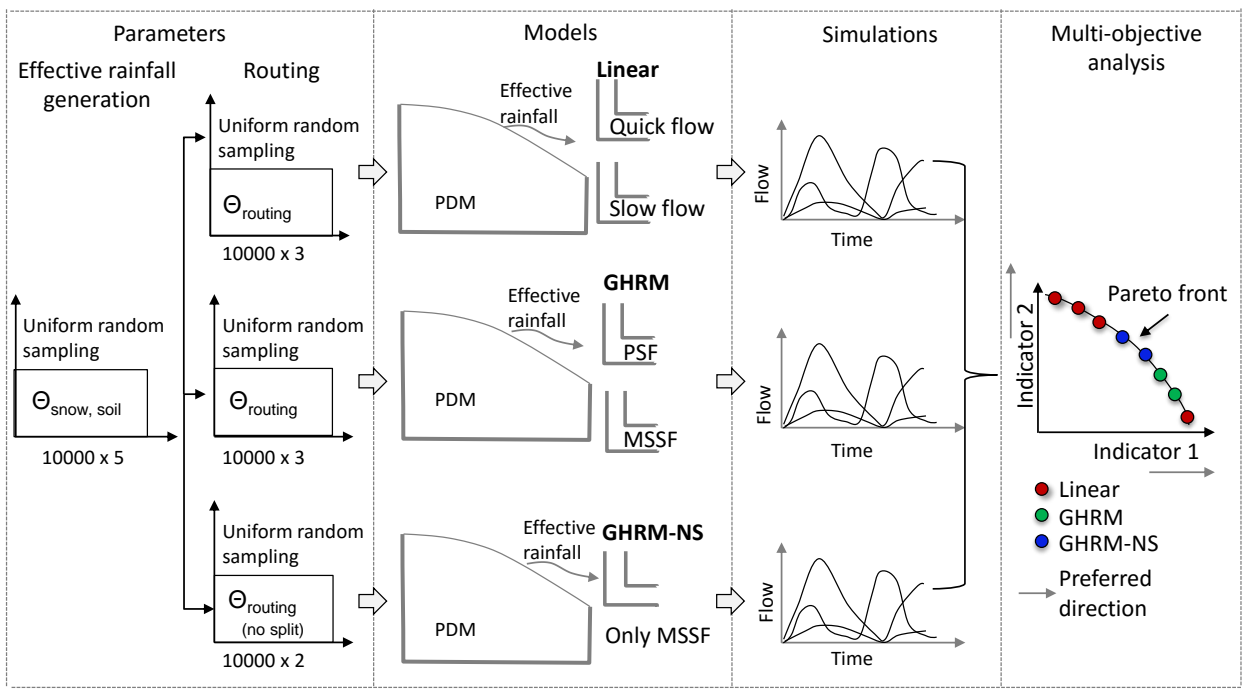

Figure 6: Model structures used in the study. The degree day method is used for snow generation. ER is generated via fill and spill mechanism from soil moisture stores with a specified probability distribution of heights. Three types of routing mechanisms are considered: Linear, GHRM, and GHRM-NS. See text for detailed description of the models and related equations. 


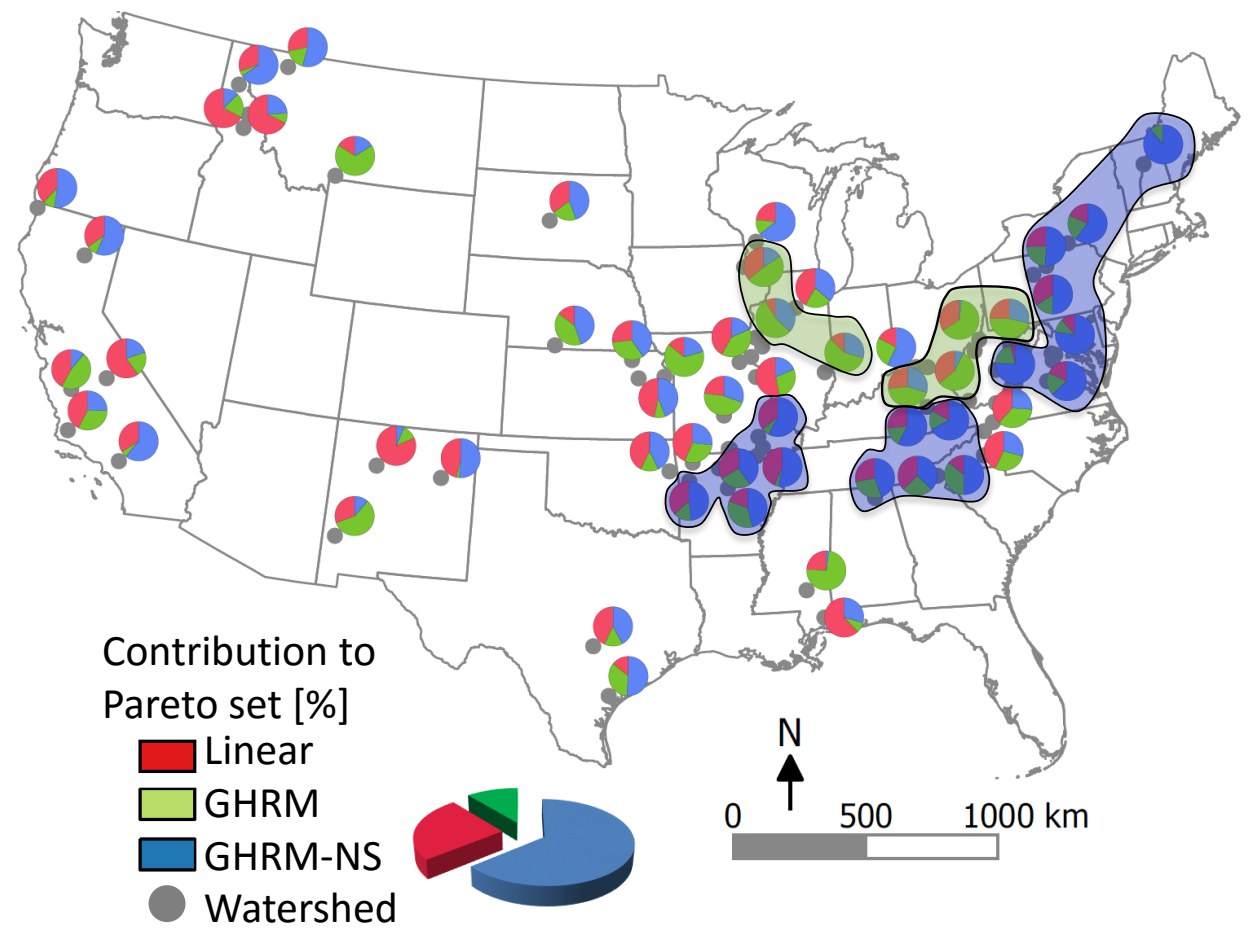

Figure 7: Contributions to the Pareto approximate sets from Linear, GHRM, and GHRMNS routing structures across the conterminous US. Regions of dominance of each model structure are marked by representative colors. Contiguous regions are shown where three or more watersheds are dominated by a routing structure. So, GHRM-NS structure dominates in the northeastern US, while GHRM dominates in some parts of mid-western US. 

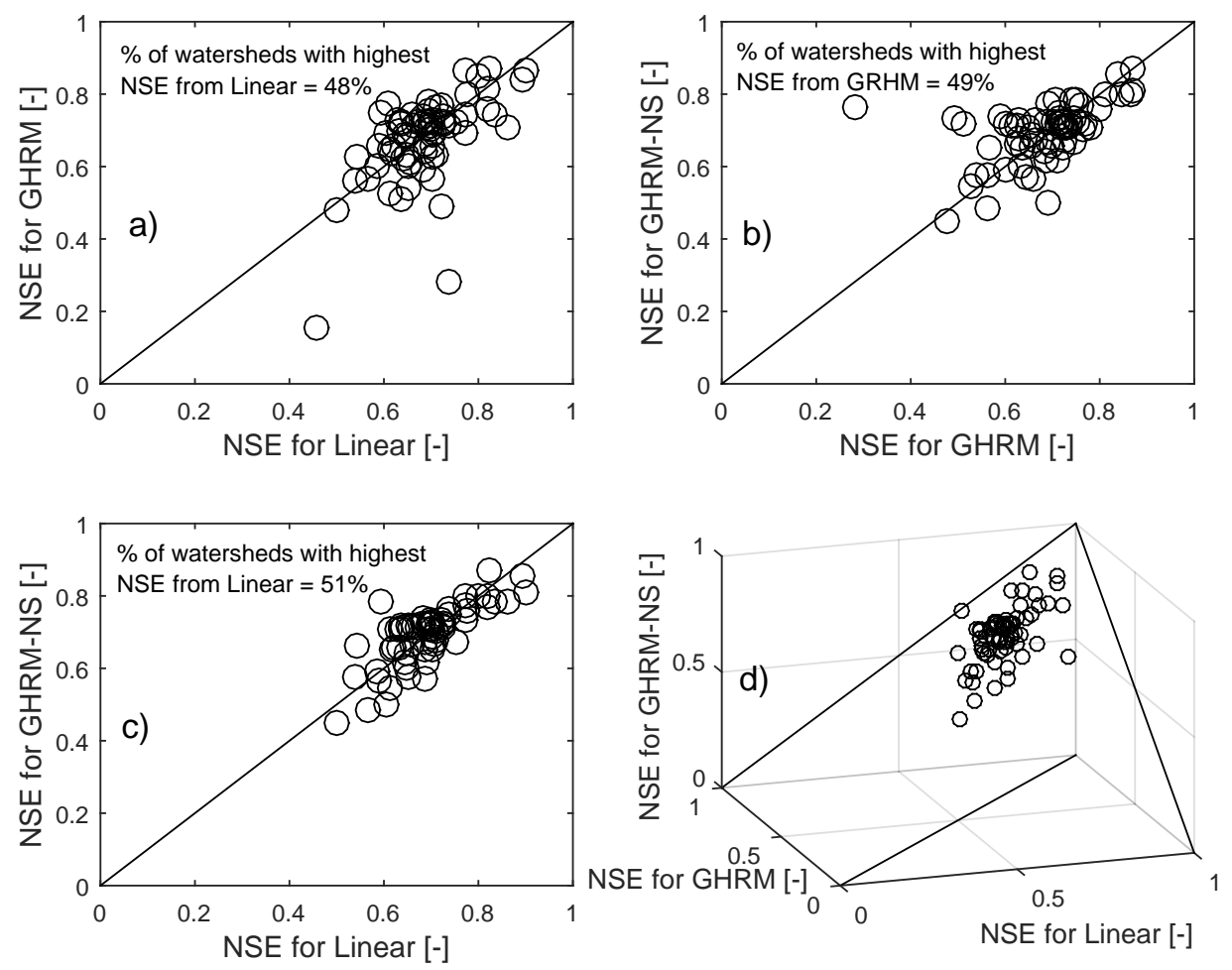

Figure 8: Highest NSE performance across Pareto approximate sets for each watershed for Linear, GHRM, and GHRM-NS models. (a-c) NSE for GHRM vs. Linear, GHRM-NS vs. GHRM, GHRM-NS vs. Linear, respectively. (d) Visualizing best NSE performance in the three dimensional space with NSE for Linear, GHRM, and GHRM-NS on x-axis, y-axis, and z-axis, repsectively. 

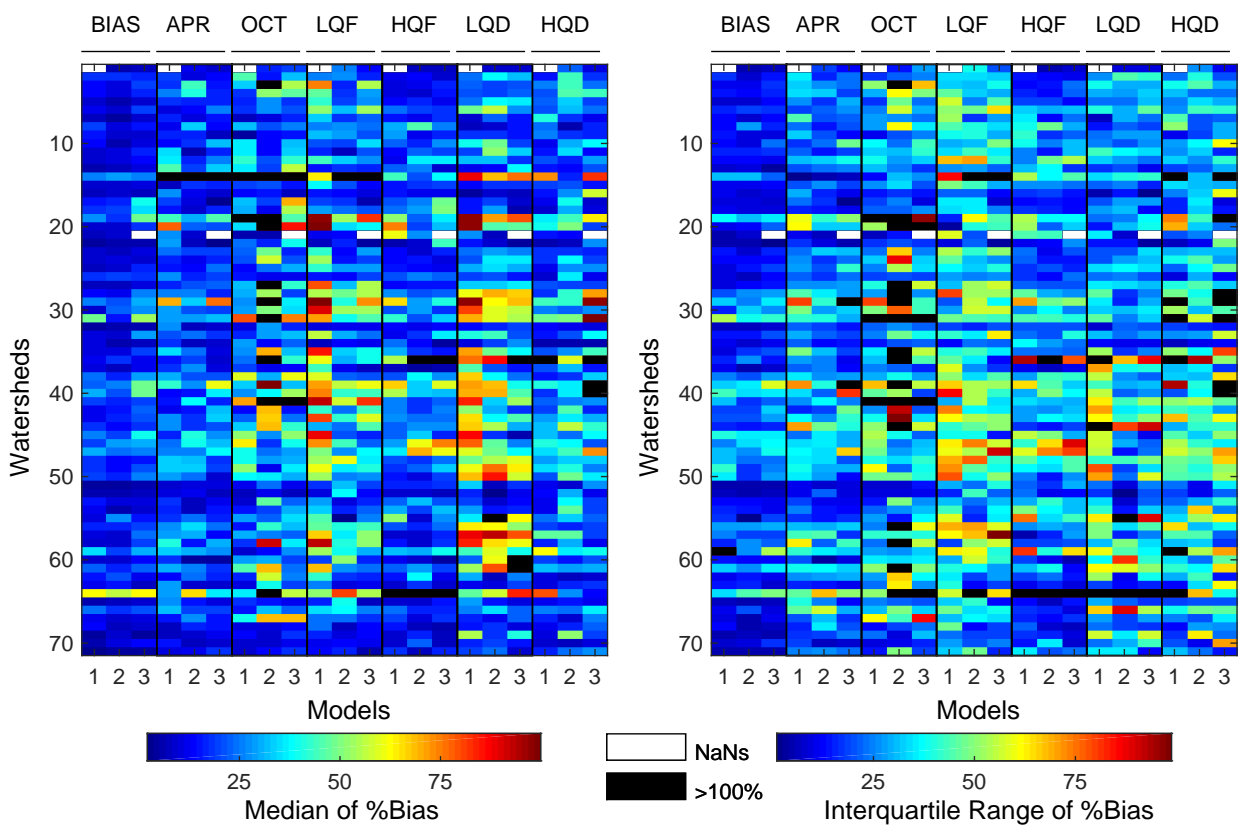

Figure 9: Performance of 1-Linear, 2-GHRM, and 3-GHRM-NS models in terms of percentage bias for the six ecological indicators and volumetric bias. For each model, the performance is assessed across all Pareto approximate sets contributed by the model. The performance is summarized as (left figure) median values of percentage bias, and (right figure) interquartile range of percentage bias for each watershed-model combination. Watersheds are shown on the y-axis, metrics are shown on the top x-axis, and models on the bottom x-axis. BIAS: volumetric bias, APR: minimum April flow, OCT: maximum October flow, LQF: low flow pulse count, HQF: high flow pulse count, LQD: low flow pulse duration, HQD: high flow pulse duration. 

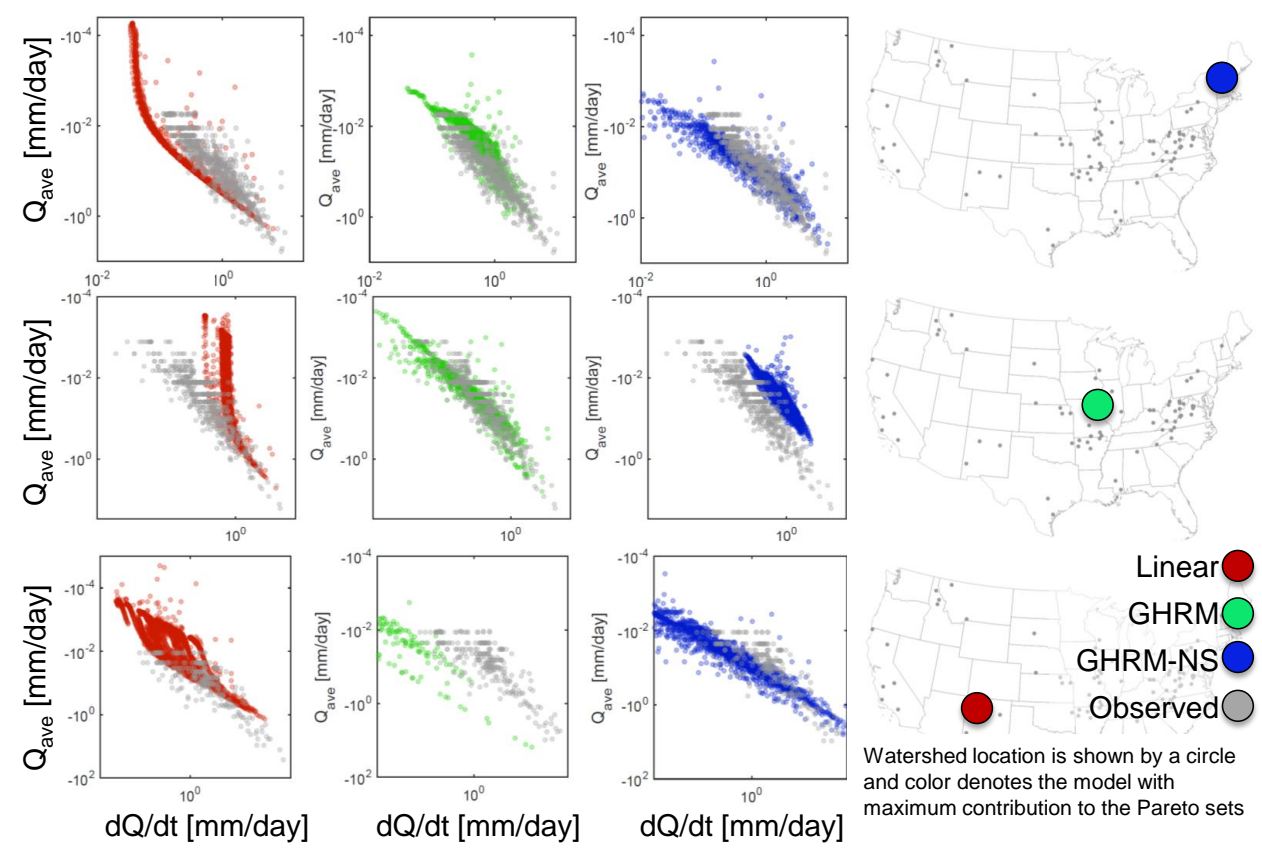

Figure 10: Qualitative comparison of the ability of the three models to reproduce the observed recession response. This is captured by the $d Q / d t$ (x-axis) versus $Q_{\text {ave }}$ (y-axis) curves for each recession event. The comparison is shown for the parameter set with highest NSE in the Pareto approximate sets of each model structure. Plots are shown for three selected watersheds for the three routing models: Linear, GHRM, and GHRMNS, structures dominated the Pareto approximate front. In each subplot, recession events simulated by the parameter sets contributed by Linear, GHRM, and GHRM-NS, are shown by red, green, and blue circles, respectively. Overlain are the observed relationships shown as grey circles. 


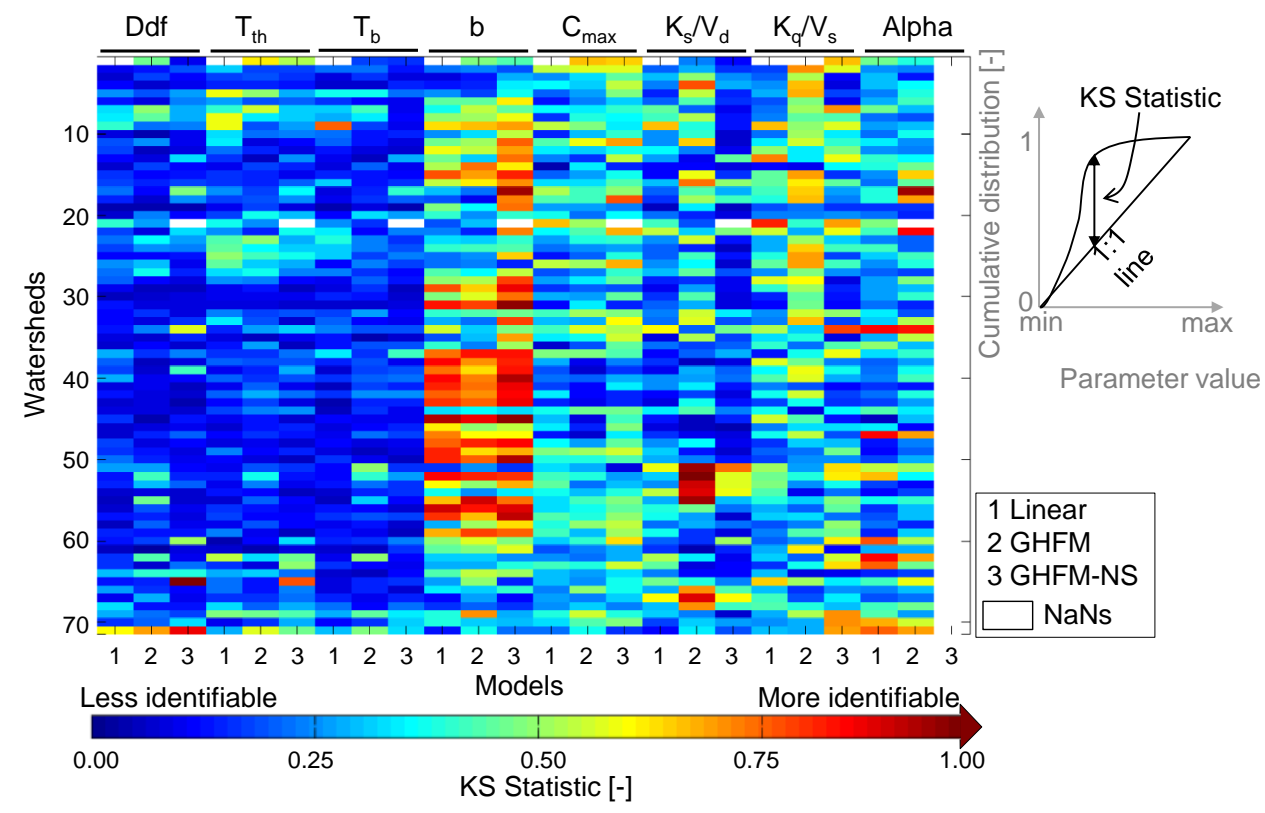

Figure 11: Identifiability of hydrologic model parameters for 1-Linear, 2-GHRM, and 3GHRM-NS model structures expressed as the Kolmogorov-Smirnov $(K S)$ statistic. For each parameter, the $K S$ statistic computes the maximum distance between the apriori distribution and the distribution across the Pareto approximate sets contributed by each model. The $K S$ statistic is shown using a color scheme such that blue (red) values denote the lowest (highest) values. Watersheds are shown on the y-axis, parameters are shown on the top x-axis, and models are shown on the bottom $\mathrm{x}$-axis. 


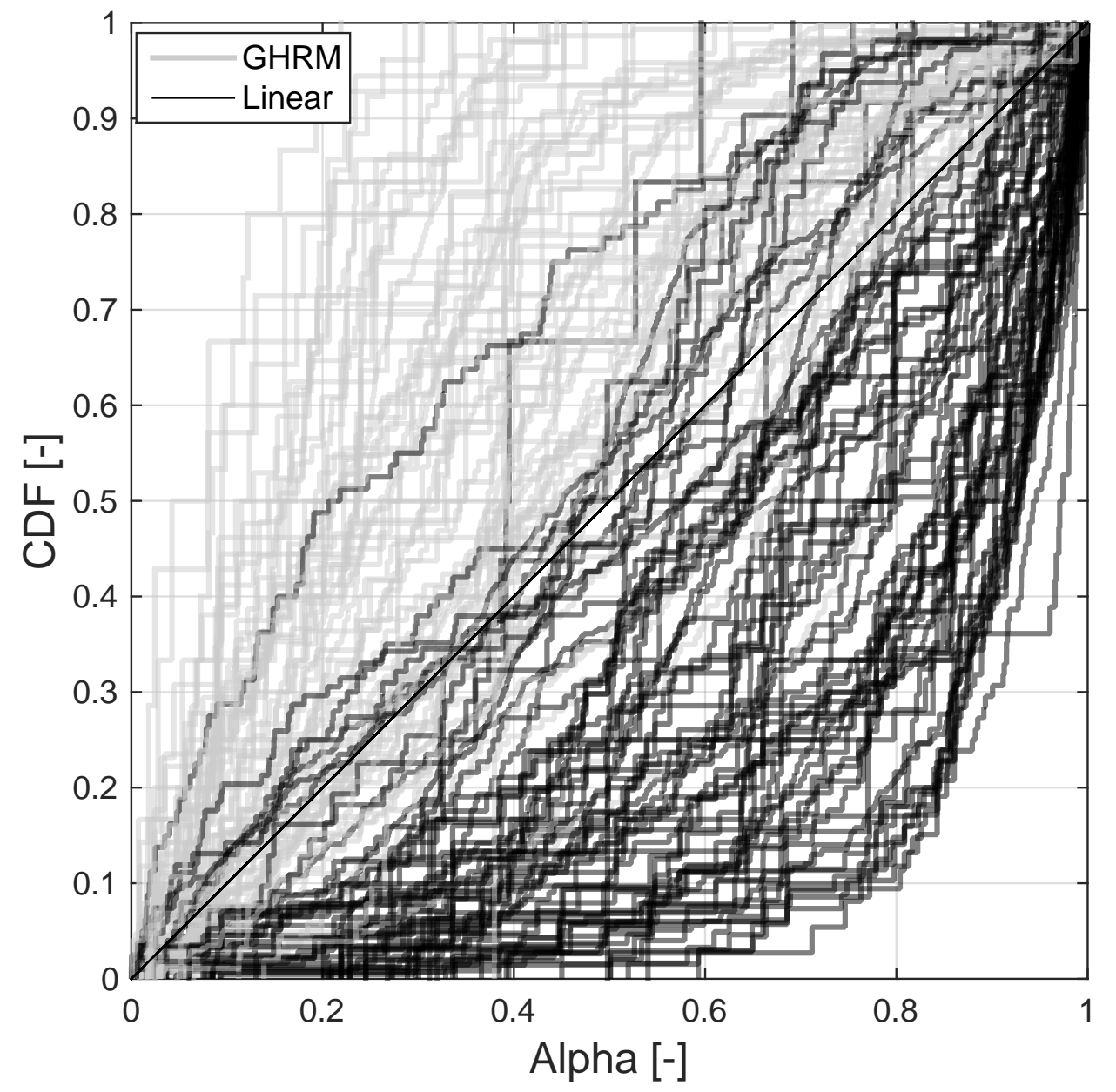

Figure 12: Cumulative distribution function $(\mathrm{CDF})$ of the split parameter, $\alpha$, across the Pareto approximate sets contributed by the Linear (black lines) and GHRM (grey lines) structures. Each line represents a watershed. 


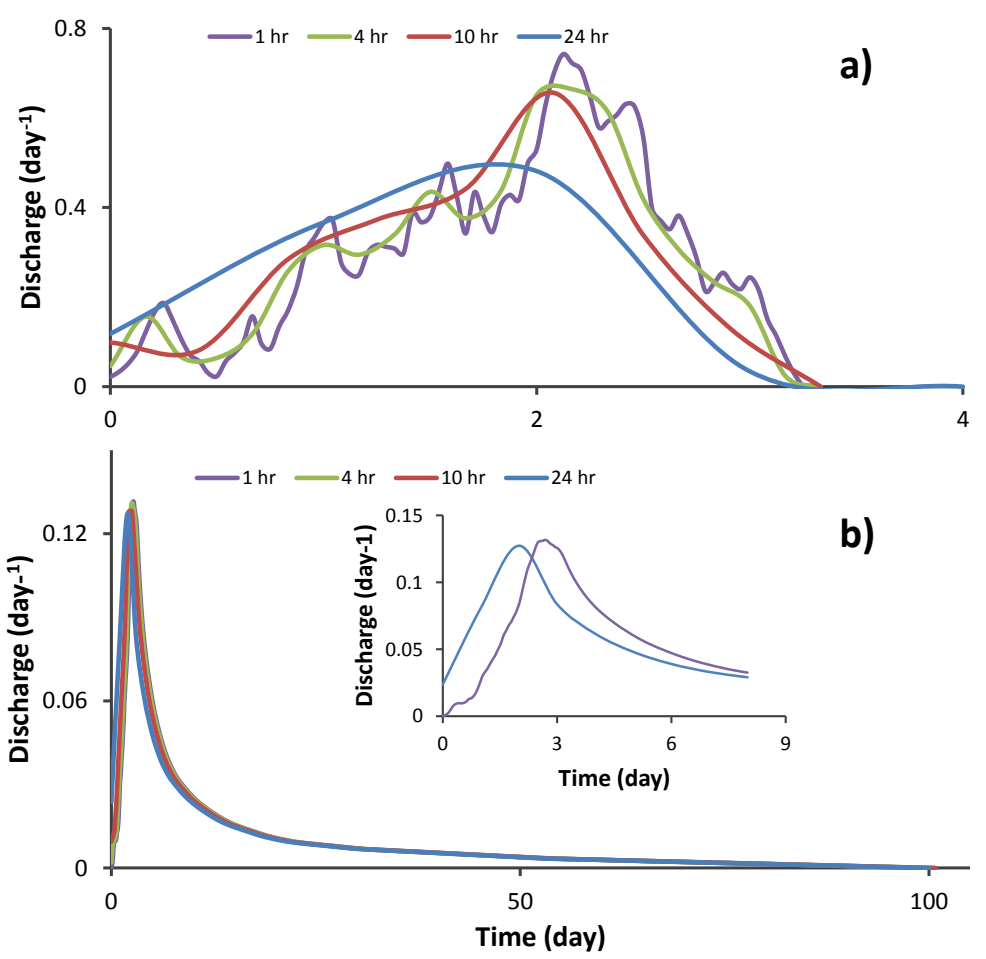

Figure 13: PSFIUHs (a) and MSSFIUHs (b) obtained for Ohio Brush catchment by considering different time steps. $V_{s}$ and $V_{d}$ were set at $1 \mathrm{~km} / \mathrm{hr}$ and $0.033 \mathrm{~km} / \mathrm{hr}$, respectively. It can be noticed that PSFIUH, unlike MSSFIUH is quite sensitive to the chosen time step. However, during the initial flow period MSSFIUH is quite sensitive to time-step (see the inset). Note that flow accumulation threshold equals to 100 pixels was chosen for channel network extraction. 

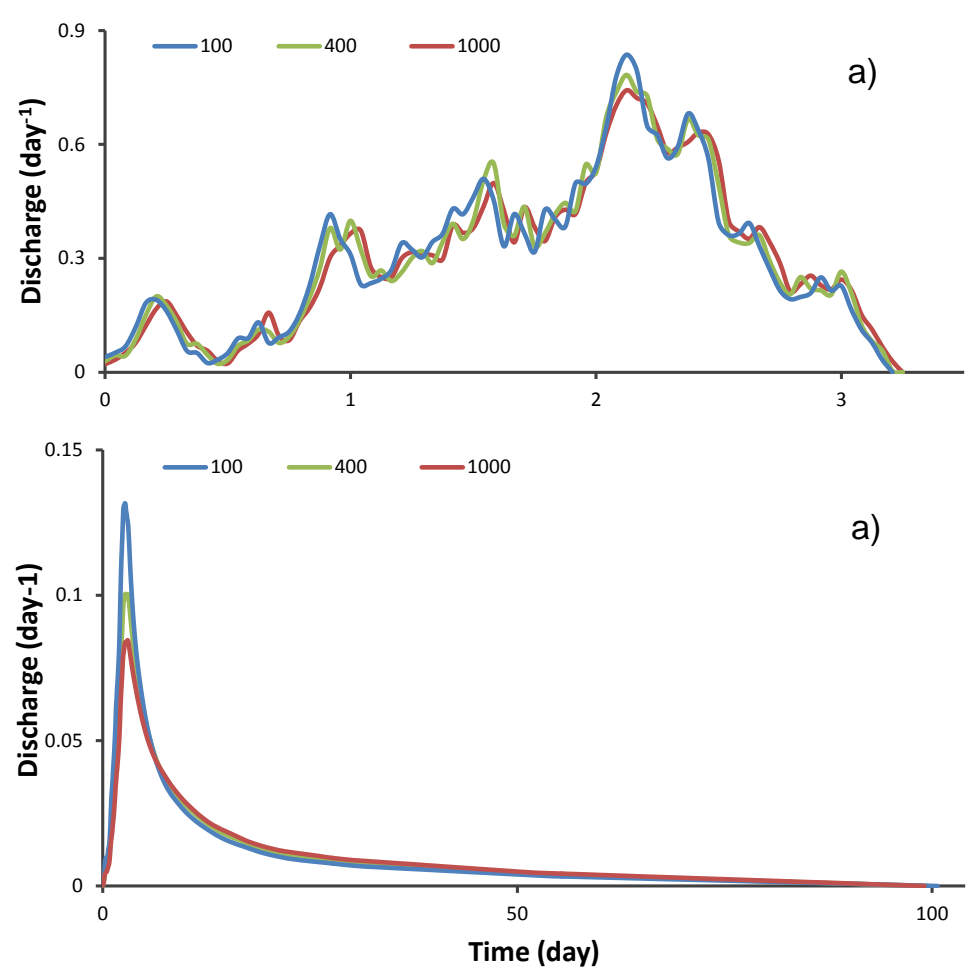

Figure 14: Sensitivity of PSFIUH and MSSFIUH to flow accumulation threshold. a) Visual inspection reveal that PSFIUH is slightly insensitive to flow accumulation threshold. Its shape becomes smoother as flow accumulation threshold increases. a) MSSFIUH, however, is sensitive to flow accumulation threshold. In particular, the peak of MSSFIUH is higher for lower flow accumulation threshold, and vice versa. $V_{s}$ and $V_{d}$ were $1 \mathrm{~km} / \mathrm{hr}$ and 0.033 $\mathrm{km} / \mathrm{hr}$, respectively for the analysis. 
Table 1: Apriori parameters ranges for model parameters used in the study.

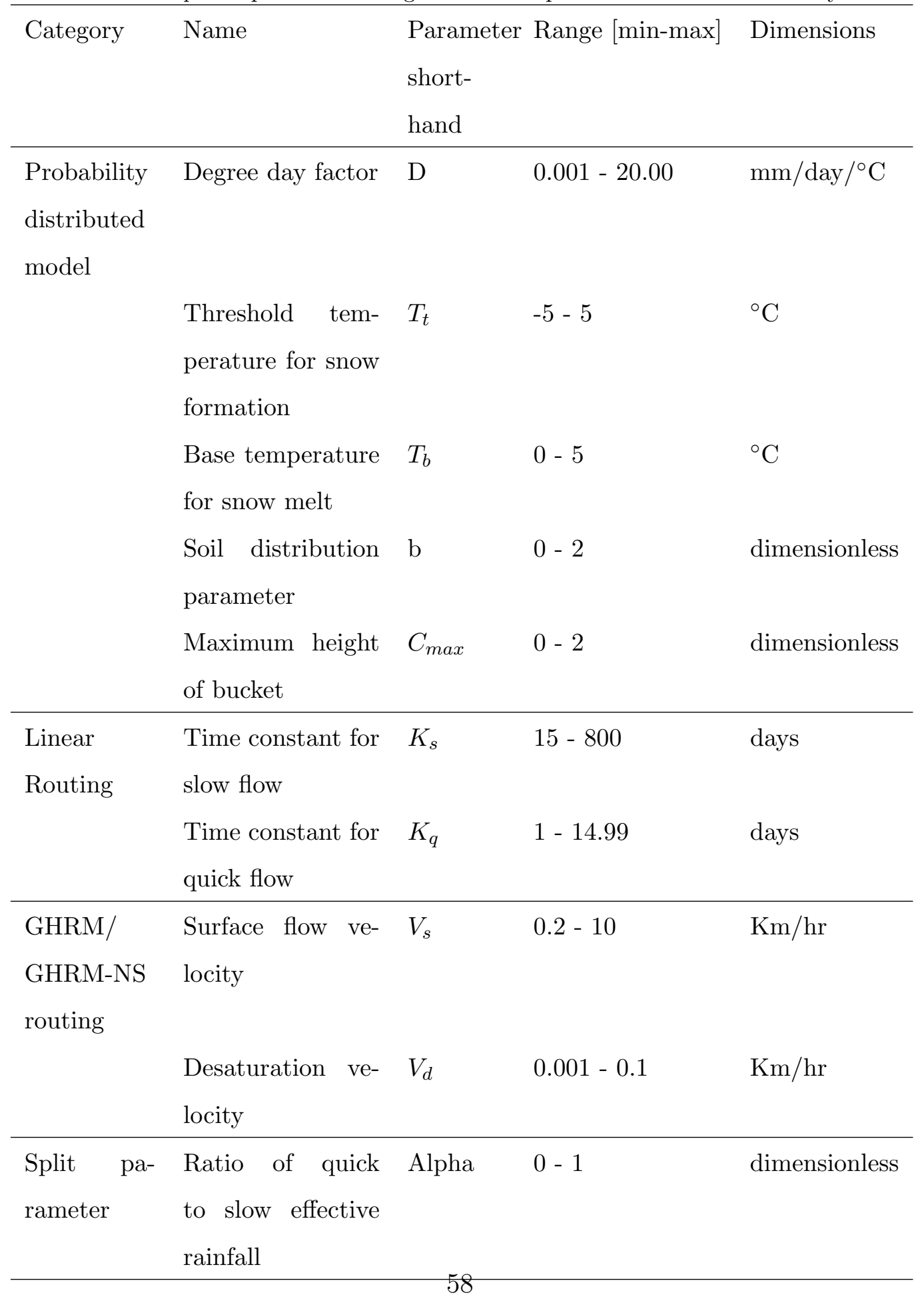


Table 2: Ecologically relevant metrics considered for performance evaluation based on [44]

\begin{tabular}{|c|c|c|c|}
\hline Metric & Type & Definition & Units \\
\hline Minimum April flows & Magnitude (low) & $\begin{array}{l}\text { Mean minimum monthly flow for April } \\
\text { across time period of study }\end{array}$ & $\mathrm{mm} /$ day \\
\hline Maximum October flows & Magnitude (high) & $\begin{array}{l}\text { Mean maximum monthly flow for August } \\
\text { across time period of study }\end{array}$ & $\mathrm{mm} /$ day \\
\hline Low flow pulse count & Frequency (low) & $\begin{array}{l}\text { Number of annual occurrences during } \\
\text { which the magnitude of flow remains be- } \\
\text { low a lower threshold. Hydrologic pulses } \\
\text { are defined as those periods within a year } \\
\text { in which the flow drops below } 25^{\text {th }} \text { per- } \\
\text { centile of all daily values for the time pe- } \\
\text { riod }\end{array}$ & per year \\
\hline High flow pulse count & Frequency (high) & $\begin{array}{l}\text { Same as above where high pulse is defined } \\
\text { as three times the median daily flow }\end{array}$ & per year \\
\hline Low flow pulse duration & Duration (low) & $\begin{array}{l}\text { Mean duration of low flow pulses defined } \\
\text { above }\end{array}$ & days \\
\hline High flow pulse duration & Duration (high) & $\begin{array}{l}\text { Mean duration of high flow pulses with } \\
\text { high flow cutoff at } 75^{\text {th }} \text { percentile of the } \\
\text { daily flows of the entire record }\end{array}$ & days \\
\hline
\end{tabular}


Table 3: Median and interquartile range of model performance estimated for the Pareto approximate sets contributed by each model. Estimates are shown for each of the eight performance metrics across all watersheds.

\begin{tabular}{|c|c|c|c|c|c|c|c|}
\hline \multirow[t]{2}{*}{ Metric } & \multirow[t]{2}{*}{ Dimensions } & \multicolumn{3}{|c|}{ Median performance } & \multicolumn{3}{|c|}{ Interquartile range of performance } \\
\hline & & Linear & GHRM & GHRM-NS & Linear & GHRM & GHRM-NS \\
\hline Nash Sutcliffe & - & 0.47 & 0.41 & 0.52 & 0.17 & 0.17 & 0.16 \\
\hline \multicolumn{8}{|l|}{ Efficiency } \\
\hline Volumetric & $\%$ & 12 & 11 & 17 & 10 & 9 & 15 \\
\hline \multicolumn{8}{|l|}{ bias } \\
\hline Bias in min- & $\%$ & 24 & 12 & 17 & 14 & 15 & 14 \\
\hline imum April & & & & & & & \\
\hline \multicolumn{8}{|l|}{ flows } \\
\hline Bias in maxi- & $\%$ & 27 & 24 & 30 & 21 & 49 & 23 \\
\hline mum October & & & & & & & \\
\hline \multicolumn{8}{|l|}{ flows } \\
\hline Bias in low & $\%$ & 43 & 27 & 25 & 40 & 22 & 27 \\
\hline flow pulse & & & & & & & \\
\hline \multicolumn{8}{|l|}{ count } \\
\hline Bias in high & $\%$ & 21 & 18 & 19 & 15 & 15 & 17 \\
\hline flow pulse & & & & & & & \\
\hline \multicolumn{8}{|l|}{ count } \\
\hline Bias in low & $\%$ & 33 & 35 & 28 & 47 & 41 & 35 \\
\hline flow pulse & & & & & & & \\
\hline \multicolumn{8}{|l|}{ duration } \\
\hline Bias in high & $\%$ & 20 & 30 & 22 & 16 & 22 & 19 \\
\hline flow pulse du- & & & & & & & \\
\hline ration & & & & & & & \\
\hline
\end{tabular}


Table 4: Median and interquartile range of the Kolmogorov-Smirnov $(K S)$ statistic across all watersheds. The $K S$ statistic is estimated for each parameter-model combination.

\begin{tabular}{lllllll}
\hline \multirow{2}{*}{ Parameter } & \multicolumn{3}{c}{ Median performance } & \multicolumn{3}{c}{ Interquartile range of performance } \\
& Linear & GHRM & GHRM-NS & Linear & GHRM & GHRM-NS \\
\hline $\mathrm{D}$ & 0.14 & 0.14 & 0.12 & 0.12 & 0.15 & 0.15 \\
$T_{t}$ & 0.17 & 0.18 & 0.19 & 0.18 & 0.12 & 0.19 \\
$T_{b}$ & 0.13 & 0.16 & 0.14 & 0.13 & 0.10 & 0.10 \\
$\mathrm{~b}$ & 0.45 & 0.49 & 0.63 & 0.44 & 0.36 & 0.38 \\
$C_{\max }$ & 0.31 & 0.32 & 0.41 & 0.17 & 0.18 & 0.18 \\
$K_{s} / V_{d}$ & 0.25 & 0.34 & 0.14 & 0.15 & 0.32 & 0.19 \\
$K_{q} / V_{s}$ & 0.30 & 0.42 & 0.34 & 0.20 & 0.29 & 0.31 \\
$\alpha$ & 0.26 & 0.33 & $\mathrm{NaN}$ & 0.20 & 0.23 & $\mathrm{NaN}$ \\
\hline
\end{tabular}

